\title{
$\$$ Research Square \\ Relationship Between Neuroendocrine and Immune Gene Expression in Small Cell Lung Cancer
}

\section{Ling Cai ( $\nabla$ ling.cai@utsouthwestern.edu )}

The University of Texas Southwestern Medical Center

\section{Hongyu Liu}

The University of Texas Southwestern Medical Center

\section{fang huang}

The University of Texas Southwestern Medical Center

Junya Fujimoto

MD Anderson Cancer Center

\section{Luc Girard}

The University of Texas Southwestern Medical Center Jun Chen

Tianjin Medical University General Hospital

\section{Yongwen Li}

Tianjin Medical University General Hospital

\section{Yu-an Zhang}

The University of Texas Southwestern Medical Center Dhruba Deb

The University of Texas Southwestern Medical Center

\section{Victor Stastny}

The University of Texas Southwestern Medical Center

\section{Christin Kuo}

Stanford University

\section{Gaoxiang Jia}

The University of Texas Southwestern Medical Center

\section{Chendong Yang}

The University of Texas Southwestern Medical Center

\section{Wei Zou}

Roche (United States)

\section{Adeeb Alomar}

The University of Texas Southwestern Medical Center

\section{Kenneth Huffman}

University of Texas Southwestern Medical Center

\section{Mahboubeh Papari-Zareei}


The University of Texas Southwestern Medical Center

\section{Lin Yang}

Chinese Academy of Medical Sciences \& Peking Union Medical College

\section{Benjamin Drapkin}

The University of Texas Southwestern Medical Center

\section{Esra Akbay}

UT Southwestern

\section{David Shames}

Roche (United States)

\section{Ignacio Wistuba}

M. D. Anderson Cancer Center

\section{Tao Wang}

The University of Texas Southwestern Medical Center https://orcid.org/0000-0002-4355-149X

\section{Guanghua Xiao}

UT Southwestern Medical Center

\section{Ralph DeBerardinis}

The University of Texas Southwestern Medical Center https://orcid.org/0000-0002-2705-7432

John D. Minna

University of Texas Southwestern Medical Center https://orcid.org/0000-0002-7776-0767

\section{Yang Xie}

The University of Texas Southwestern Medical Center

\section{Adi Gazdar}

The University of Texas Southwestern Medical Center

\section{Article}

Keywords: small cell lung cancer, neuroendocrine, immune gene expression, lung cancer

Posted Date: August 4th, 2020

DOI: https://doi.org/10.21203/rs.3.rs-50416/v1

License: (a) (i) This work is licensed under a Creative Commons Attribution 4.0 International License. Read Full License

Version of Record: A version of this preprint was published at Communications Biology on March 9th, 2021. See the published version at https://doi.org/10.1038/s42003-021-01842-7. 
1 Relationship Between Neuroendocrine and Immune Gene Expression in Small Cell Lung Cancer

2 Ling Cai ${ }^{1,2,3,{ }^{*}}$, Hongyu Liu ${ }^{1,4}$, Fang Huang ${ }^{2}$, Junya Fujimoto ${ }^{5}$, Luc Girard ${ }^{3,6,7}$, Jun Chen ${ }^{4,8}$, Yongwen Li ${ }^{4}$, Yu3 an Zhang ${ }^{6}$, Dhruba Deb ${ }^{6}$, Victor Stastny ${ }^{6}$, Christin S. Kuo ${ }^{9}$, Gaoxiang Jia ${ }^{1}$, Chendong Yang ${ }^{2}$, Wei Zou ${ }^{10}$, 4 Adeeb Alomar ${ }^{6}$, Kenneth Huffman ${ }^{6}$, Mahboubeh Papari-Zareei ${ }^{6}$, Lin Yang ${ }^{11}$, Benjamin Drapkin ${ }^{3,6,12}$, Esra $5 \quad$ Akbay $^{13}$, David S. Shames ${ }^{10}$, Ignacio I. Wistuba ${ }^{5}$, Tao Wang ${ }^{1,3}$, Guanghua Xiao ${ }^{1,3,14}$, Ralph J.

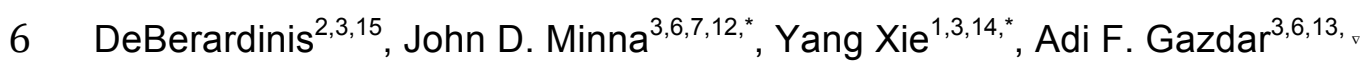

7

8 Affiliations

9

${ }^{1}$ Quantitative Biomedical Research Center, Department of Population and Data Sciences, UT Southwestern Medical Center, Dallas, TX 75390, USA.

12

${ }^{2}$ Children's Research Institute, UT Southwestern Medical Center, Dallas, TX 75390, USA.

${ }^{3}$ Simmons Comprehensive Cancer Center, UT Southwestern Medical Center, Dallas, TX 75390, USA.

${ }^{4}$ Tianjin Key Laboratory of Lung Cancer Metastasis and Tumor Microenvironment, Tianjin Lung Cancer Institute, Tianjin Medical University General Hospital, Tianjin 300052, People’s Republic of China.

${ }^{5}$ Department of Translational Molecular Pathology, University of Texas MD Anderson Cancer Center, Houston, TX 77054, USA.

22

${ }^{6}$ Hamon Center for Therapeutic Oncology Research, University of Texas Southwestern Medical Center, Dallas, TX 75390, USA.

${ }^{7}$ Department of Pharmacology, UT Southwestern Medical Center, Dallas, TX 75390, USA. 
${ }^{8}$ Department of Lung Cancer Surgery, Tianjin Lung Cancer Institute, Tianjin Medical University General 29 Hospital, Tianjin 300052, People's Republic of China.

30

$31{ }^{9}$ Department of Pediatrics, Stanford University, CA 94305, USA

32

$33{ }^{10}$ Department of Oncology Biomarker Development, Genentech Inc., South San Francisco, CA 94080, USA 34

${ }^{11}$ Department of Pathology, National Center/Cancer Hospital, Chinese Academy of Medical Sciences and Peking Union Medical College, Beijing, China

37

${ }^{12}$ Department of Internal Medicine, University of Texas Southwestern Medical Center, Dallas, TX 75390, 39 USA.

40

${ }^{13}$ Department of Pathology, UT Southwestern Medical Center, Dallas, TX 75390, USA.

42

${ }^{14}$ Department of Bioinformatics, University of Texas Southwestern Medical Center, Dallas, TX 75390, USA. 44 45 46 47 48

$49-$ Deceased

50

51 *Correspondence to Ling.Cai@UTSouthwestern.edu, John.Minna@UTSouthwestern.edu and

52 Yang.Xie@UTSouthwestern.edu 


\section{ABSTRACT}

55 Small cell lung cancer (SCLC) is classified as a high-grade neuroendocrine (NE) tumor, but a subset of 56 SCLC has been termed "variant" due to the loss of NE characteristics. In this study, we computed NE 57 scores for patient-derived SCLC cell lines and xenografts, as well as human tumors. We aligned NE 58 properties with transcription factor-defined molecular subtypes. Then we investigated the different immune 59 phenotypes associated with high and low NE scores. We found repression of immune response genes as a shared feature between classic SCLC and pulmonary neuroendocrine cells of the healthy lung. With loss of NE fate, variant SCLC tumors regain cell-autonomous immune gene expression and exhibit higher tumorimmune interactions. Pan-cancer analysis revealed this NE lineage-specific immune phenotype in other cancers. Additionally, we observed MHC I re-expression in SCLC upon development of chemoresistance. These findings provide a new framework to guide design of treatment regimens in SCLC.

\section{INTRODUCTION}

Small cell lung cancer (SCLC), accounting for $15 \%$ of lung cancer cases, with a 5 -year survival of $6 \%$, is designated by the US Congress as a "recalcitrant cancer" $(1,2)$ SCLC is classified as a high-grade neuroendocrine (NE) tumor (3). A large fraction of SCLC tumors are driven by ASCL1, a lineage oncogene also important for pulmonary neuroendocrine cell (PNEC) fate determination $(4,5)$. In healthy lung tissue, PNECs are rare and dormant (6), whereas upon lung injury, some act as stem cells to regenerate surrounding epithelial cells (7). SCLC occurs primarily in heavy smokers, but despite the very high mutation burden (8-10) from SCLC genomes predicted to contribute an ample supply of neoantigens, SCLCs express low levels of major histocompatibility complex class I (MHC I) proteins to present tumor-specific antigens $(11,12)$. This could explain why, among various types of cancer, checkpoint-blockade immunotherapy (CBI) underperforms in SCLC $(13,14)$.

Thirty-five years ago, it was observed that by contrast to "classic" SCLC cell lines (which grew in tissue culture as floating cell aggregates), a subset of patient-derived SCLC lines behaved differently - growing as adherent monolayers in culture, with morphologically larger cells, more prominent nucleoli, and expressed few or no NE markers $(15,16)$. These characteristics led such tumors to be termed "variant" or "non-NE" 
SCLC. Many of these variant SCLC lines were established from patients whose tumors had acquired

resistance to chemotherapy and clinically relapsed, a context in which genomic MYC amplification was also noted to be more frequent (17). Notch activation had been shown to mediate the transition from "classic" to "variant" subtypes and accounts for the intratumoral heterogeneity commonly seen in SCLC (18). different levels of NE markers (19-21).

\section{RESULTS}

Relationship between NE scores and SCLC molecular subtypes

Using the 50-gene NE signature updated with all available SCLC-related RNA-seq data (Table S1), we computed NE scores for patient-derived SCLC lines and xenografts (PDXs) as well as four independent patient tumor datasets (including one newly generated for this study) (Tables 1 and S2). We examined the relationship between NE scores and expression of SCLC molecular subtype-specific TFs as proposed by Rudin et al (Figure 1a-b). Our findings are largely consistent with the previous proposal that assigns ASCL1+ and NEUROD1+ SCLCs to NE subtypes and POU2F3+ and YAP1+ SCLCs to non-NE subtypes. However, we note some discrepancies. First, we found that while expression of ASCL1 and NEUROD1 seems to be mutually exclusive in cell lines, they seem to co-express in many of the tumor samples; secondly, in "George_2015", “Jiang_2016” and our own dataset, we have observed rare POU2F3+ samples that have high NE scores. 
111 With serially sectioned formalin fixed paraffin embedded (FFPE) slides from 9 out of the 18 tumors for which

112 we had performed expression profiling, we examined the tumors with hematoxylin and eosin (H\&E) staining 113 as well as immunohistochemistry (IHC) staining of ASCL1, NEUROD1 and POU2F3 (Figures 1c-f). The 114 high NE-score tumors exhibited predominantly classic SCLC morphology with dark nuclei, scant cytoplasm 115 and inconspicuous nucleoli. Notably, this was not only seen in ASCL1+ tumors (for example, SCLC-04, NE 116 score 0.4 ) but also in the POU2F3+ tumor with a positive NE-score (SCLC-15, NE score 0.26) (Figure 1c). 117 On the other hand, while we observed variant morphology in tumors with low NE scores, we noticed 118 intratumoral heterogeneity. In a tumor weakly positive for ASCL1 (SCLC-20, NE score -0.05), the ASCL1high regions were found to be more "classic"-like whereas the ASCL1-low regions were more "variant"-like

(Figure 1d). Our IHC-based quantifications largely agree with the microarray gene expression assessments

121 (Figure 1e). Tumors that were found to express both ASCL1 and NEUROD1 stained positive for both 122 markers as well. In addition, intratumoral heterogeneity was commonly found within such tumors, where 123 there are areas with high expression of both TFs but also areas with expression of only one TF (Figure 1f).

125 Immune gene repression is a NE lineage-specific property

126 We performed correlation between NE scores and SCLC transcriptomic data to identify gene expression 127 changes associated with the NE program. Not surprisingly, gene ontology (GO) analyses revealed genes 128 related to the neuronal system as highly expressed in high NE-score samples (Figures S1a-b). By contrast, 129 genes negatively associated with NE score were enriched for GO terms related to immune response, and 130 this was observed in both the cell line and human tumor datasets (Figure S1c-d). We also performed gene 131 set enrichment analysis (GSEA) (23) with a variety of gene set libraries collected by Enrichr (24). Consistent 132 with previous report that Notch signaling dependent REST (Neuron-Restrictive Silencer Factor) activation 133 represses neuronal gene expression in variant SCLC (18), we found REST targets (i.e. repressed by REST) 134 are abundantly expressed in high NE-score SCLCs. On the other hand, interferon-stimulated genes (ISGs) 135 are found to highly express in the low NE-score (variant) SCLC samples (Figures 2a-b). As NFKB signaling 136 mediates activation of ISGs, we examined reverse phase protein array (RPPA) data from the cancer cell 
137 line encyclopedia (CCLE) (25) and found higher levels of activating serine 536 phosphorylation on p65 (26)

138 in low NE-score SCLC lines (Figure 2c).

139

140 Our 50-gene signature derived from lung cancer cell line mRNA data (Table S1) contains several genes

141 with immune related functions that were found to highly express in variant SCLC. Some are involved in 142 cytokine signaling; for example, IL18 encodes for a proinflammatory cytokine (27), and OSMR encodes for 143 a receptor for oncostatin M and IL-31 (28). Furthermore, many of these genes are involved with 144 immunosuppressive processes, including NT5E (29), TGFBR2 (30), ANXA1 (31), EPHA2 (32), HFE (33) 145 and LGALS3 (34). Our pathway analyses indicates that beyond these genes included in the NE expression 146 signature, there is a broad immune program concertedly upregulated in low NE-score SCLC samples. We extended our analysis to a few immune gene sets that were previously identified to express cell autonomously in cancer. These gene sets include the following: SPARCS genes (stimulated 3 prime antisense retroviral coding sequences) reported to express in mesenchymal tumors and mediate interferongamma signal amplification (35); "parainflammation" (PI) genes in epithelial tumor cells (36); and senescence-associated secretory phenotype (SASP) genes (37) that reinforce the senescence arrest, alter the microenvironment, and trigger immune surveillance of the senescent cells (38). We observed that the expression these genes also negatively correlate with NE scores in SCLC despite little overlap among 154 genes in these various sets (Figure S2).

156 While the expression of neuronal program genes in in high NE-score SCLCs can be attributed to the NE 157 lineage, we examined single-cell RNA-seq (scRNA-seq) data from the healthy human lung epithelial cells 158 (39) to check whether the expression repression of ISGs is also a lineage-specific phenomenon that could 159 be observed in PNECs rather than being cancer-specific. Consistent with the previous report that ASCL1 160 negatively regulate YAP1 during neuronal differentiation (40), the highest expression of ASCL1 and lowest 161 expression of YAP1 were observed in PNECs, relative to other cell types. We confirmed that while PNECs 162 have increased expression of REST target genes, ISGs are indeed repressed as well (Figure 2d and S3a). 163 Additionally, we specifically examined interferon receptors in PNECs and found that they also have the 164 lowest expression in PNECs (Figures 2d), suggesting that besides repression of basal ISG expression, in 
165 the presence of interferon stimulation, PNECs would also be less primed for further activation of ISGs. It

166 has been estimated that $10 \%$ of the genes in the human genome have the potential to be regulated by IFN,

167 many ISGs work in immune defense against viral infection, but some could be hijacked by viruses (41). As

168 some PNECs are rare stem cells, we reason that ISG repression could lower their risk from viral infection. In

169 the context of the current COVID-19 pandemic, we examined scRNA-seq data from Ouadah et al., who

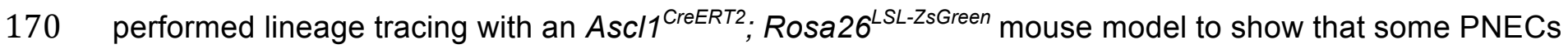

171 can transdifferentiate into other cell types (7). Figure S3b generated with their data shows that AT2 and

172 ciliated cells originated from PNECs in this model have lost Ascl1 but increased Yap1 expression. Ly6e and

173 Tmprss2, genes involved in coronavirus defense (42) and hijacked entry (43) respectively, were also

174 upregulated.

175

176 Increased tumor-immune interaction in low NE-score SCLC tumor samples

177 It has been long observed that expression of MHC I is low in SCLC (11). Using single sample gene set

178 enrichment analysis (ssGSEA) (44), we derived the MHC I scores for MHC I genes. From studies that had

179 collected lung tumors of different histology, MHC I scores positively correlate with PTPRC (which encodes

180 for pan-leukocyte marker CD45) levels (Figures 3a and S4a). The lowest MHC I and PTPRC gene

181 expression were found in neuroendocrine tumors, including not only SCLC but also carcinoids (Figure 3a),

182 suggesting these NE tumors with decreased MHC I have fewer immune infiltrates. In SCLC datasets, low

183 NE-score samples exhibited upregulation of MHC I genes (Figure $\mathbf{3 b}$ ) and were associated with higher

184 PTPRC expression in patient tumor datasets (Figure S4b). We also estimated immune cell infiltration by

185 deriving immune cell type-specific signature scores (45) and found that they negatively correlate with NE

186 scores in SCLC patient tumors, suggesting increased tumor-immune interaction in low NE-score tumors

187 (Figure 3c).

188

189 We saw higher expression of PD-L1 (CD274) in low NE-score SCLCs (Figure S5a). Furthermore, genes

190 from an IFN-gamma related signature that has been shown to predict PD-1 blockade response in multiple

191 cancer types (46) are highly expressed in low NE-score SCLC tumors across multiple datasets (Figure 3c).

192 We also examined a list of 21 immune checkpoint genes (47), immune suppressive cytokines (IL-10 and 
193 TGF-beta), and their receptors (48), for their association with NE scores. We found that these genes also

194 have higher expression in low NE-score SCLC tumors (Figure 3c). Finally, the expression of 995

195 immunosuppressive genes from the Human Immunosuppression Gene Atlas (47) were assessed and again,

196 the majority of these genes exhibit negative correlation between mRNA expression and NE scores across

197 different SCLC tumor datasets (Figure S5b and Table S3).

198

199 Besides gene expression-based analyses, we also performed immunohistochemistry (IHC) with our 9 SCLC 200 tumor samples to quantify tumor infiltrating CD8+ and CD4+ T cells (Table S2). Of importance, both 201 intratumoral and intertumoral heterogeneity were observed in T cell infiltration. Within the same tumor, 202 areas with low tumor ASCL1 levels exhibited more CD8+ and CD4+ T cell infiltration, whereas areas with 203 high tumor ASCL1 levels showed fewer CD8+ or CD4+ T cells (Figure 4a). Across all the SCLC tumor 204 205 206 207

208 Pan-cancer analyses for NE score expression and immune response genes.

209 These findings had prompted us to examine other cancer types to see whether immune gene repression is 210 seen in other NE tumors and whether "variant" subtype from NE lineage loss could also be observed

211 (Figure 4c). A recent study identified "SCLC-like" epithelial tumors in pan-cancer samples using a principal 212 component analysis-based approach. They found that tumors across many lineages with a higher "SCLC213 like" score had lower immune gene expression (49). We applied our NE scoring method across all cancer 214 lineages ("pan-cancer" analysis) to compute NE scores and assess their relationship with immune 215 phenotypes. In pediatric (Therapeutically Applicable Research to Generate Effective Treatments - TARGET) 216 and adult (The Cancer Genome Atlas - TCGA) pan-cancer studies (50), neuroendocrine tumor 217 neuroblastoma (NBL), as well as pheochromocytoma \& paraganglioma (PCPG) were identified as 218 containing the highest NE scores (Figures 5a-b). Tumors of glial origin, including Low Grade Glioma (LGG) 219 and Glioblastoma Multiforme (GBM) also have high NE scores. Besides these NE/glial tumors, a small 220 number of high NE-score samples were observed for bladder urothelial carcinoma (BLCA), breast invasive 
221 carcinoma (BRCA), lung adenocarcinoma (LUAD), lung squamous cell carcinoma (LUSC), pancreatic

222 adenocarcinoma (PDAC) and stomach adenocarcinoma (STAD), for which it is also known that

223 neuroendocrine tumors, while uncommon, still comprise a small proportion of the cases (Figures 5a-b).

224 Previous immunogenomic analysis had classified pan-cancer TCGA samples into six immune subtypes (51).

225 We found samples from the "immunologically quiet" subclass have the highest NE score, followed by the

226 "lymphocyte depleted" subclass (Figure 5c). We further assessed the relationship between NE scores and

227 the tumor-infiltrating lymphocytes and leukocyte regional fractions previously reported for the pan-cancer

228 samples (51), these immune metrics negatively correlate with NE scores across all samples (Figure 5d)

229 and also within specific tumor types (Figure S6).

230

231 We took a close examination of NBL using cell line expression data from CCLE (25) along with patient

232 tumor data from TARGET (52) for lineage factors ASCL1 and YAP1, REST targets, ISGs, MHC I, immune

233 cell-specific signature scores (45), Ayer et al.'s PD-1 blockade response signature (46), immune

234 checkpoints (47) and suppressive cytokines and receptors (48). The pattern for NBL (Figure 5e) highly

235 resembles that of SCLC (Figures 2a, 3b-c) suggesting the existence of a "variant" NBL subset with

236 decreased neuroendocrine features, increased cell-autonomous expression of immune genes as well as

237 increased tumor-immune interaction. Like SCLC, we also found higher levels of NFkB-p65 phosphorylation

238 in the low NE-score variant NBL cell lines (Figure $\mathbf{5 f}$ ).

239

$240 \quad$ MHC I re-expression in chemoresistant SCLC

241 As it was previously observed that variant SCLC cell lines were frequently derived from patients whose

242 tumors had relapsed on chemotherapy (17), we wondered if the development of chemo-resistance in

243 tumors was associated with the altered expression of immune genes, especially MHC I. Five sets of data

244 with origin-matched chemosensitive and chemoresistant samples were examined to address this question.

245 In 2017, using a genetically engineered mouse model (GEMM), Lim et al showed that Notch-active SCLC

246 cells were more chemoresistant (18). Using their data we found the Notch active SCLC cells had switched

247 from ASCL1+ to YAP1+, have reduced NE scores and increased expression of ISGs and MHC I genes

248 (Figure 6a). We next examined a series of preclinical models we and others have developed for human 
249 SCLC. Classic, high NE-score SCLC cell lines predominantly grow as floating aggregates in culture, but 250 contain a small proportion of cells growing adherently in a monolayer. By selecting for adherent growth, we 251 generated an adherent subline H69-AD(/NCl-H69-AD) from parental, chemosensitive H69(/NCl-H69) cells 252 (Figure 6b). Increased resistance to Cisplatin ( 10 fold) and Etoposide ( 6 fold) was observed in H69-AD 253 compared to the parental H69 cells (Figure 6c). We found H69-AD had transitioned to become a low NE254 score (-0.02) YAP1+ variant line compared to the parental high NE-score (0.91) classic ASCL1+ line. Both 255 ISGs and MHC I genes were found to have increased expression in H69-AD (Figure 6d). In a previous 256 study, Cañadas et al. also derived sublines from H69. Hepatocyte growth factor treatment was used to 257 induce mesenchymal transition of $\mathrm{H} 69$ cells, resulting in $\mathrm{H} 69-\mathrm{M}$ lines that were found to be chemoresistant 258 both in vitro and in vivo (53). From their dataset, we also found MHC I expression increased in H69-M 259 compared to parental H69 cells. There was some increase in ISGs too, but less prominent compared to 260 H69-AD from us. Notably, although YAP1 expression increased in H69-M, ASCL1 levels did not change 261 (Figure 6d). As the fourth set of data, PDX models established sequentially from SCLC tumors 262 ("Drapkin_2018”) collected before and after chemotherapy from the same patient (54) were examined. In 263 PDXs from patient MGH1518 for which chemoresistance had developed in the relapsed sample, we found 264 upregulation of MHC I, but not ISGs (Figure 6d). Of note, this relapsed sample maintained a high NE score, 265 but expressed higher levels of MYC, consistent with previous findings that MYC mediates chemoresistance 266 (54). Lastly, we generated a set of subcutaneous xenograft models from a high NE-score human SCLC cell 267 line $\mathrm{NCl}-\mathrm{H} 1436$ with or without selection for resistance to Cisplatin and Etoposide in the mice (Figure 6e). 268 Compared to the parental xenograft, the drug resistant xenografts maintained ASCL1 expression but 269 exhibited increased B2M (MHC I complex subunit), PSMB8 (immunoproteasome subunit) (Figure 6e), and MYC (Fang Huang's manuscript under review at JCI). Collectively, these findings suggest MHC I can reexpress upon development of chemoresistance - in some cases, with lineage transition; and in some other cases, accompanied by an increase in $M Y C$ expression.

274 We also checked whether expression levels of MHC I and MYC differ by tumor source and anatomical site 275 based on the "NCl/Hamon Center" patient-derived SCLC lines dataset (Figures S7). Interestingly, the 276 lowest MHC I and MYC levels were both observed for cell lines derived from primary site lung tumor 
specimens and they are all high-NE tumors, whereas higher MHC I levels were observed in SCLC lines

278 isolated from metastatic tumor samples especially those from lymph node and bone marrow. These observations remain to be validated with primary and metastatic samples from the same patients.

\section{DISCUSSION}

282 In this study, we examined NE properties of patient-derived SCLC cell lines, PDXs and human tumors 283 based on NE scores estimated from a gene expression signature. Currently, it is believed that Notch 284 activation drives the lineage transition from ASCL1+ to NEUROD1+ to YAP1+ subtype (55) whereas 285 POU2F3+ SCLC is a standalone subtype originated from tuft cells (56). While we observed mutually exclusive patterns of $A S C L 1$ and NEUROD1 expression in cell lines, their co-expression was identified in many patient tumors. Our IHC results further revealed intratumoral heterogeneity in such tumors, suggesting ongoing lineage transition in primary treatment naïve tumors. From alignment of NE scores and molecular subtype-specific TF expression, we observed rare high NE-score POU2F3+ tumors in three independent datasets, raising the possibility that POU2F3+ tumors could also arise from NE lineage.

292 Our investigation of immune phenotypes associated with variable NE scores had identified repression of 293 ISGs in classic high NE-score SCLC. While it remains to be determined what other pulmonary cells besides 294 PNECs can function as "cells of origin" for SCLC (57-60), the gene expression similarities between PNECs and SCLC suggests many of the SCLC properties could be tied to PNEC characteristics. We confirmed ISG repression in PNECs relative to other lung epithelial cells through examination of scRNA-seq data from 297 healthy human lung. ISGs provide viral defense for cells but some can be hijacked by viruses (41). Since 298 PNECs assume stem cell roles for tissue regeneration after injury (7), lowering expression of ISGs and 299 other genes involved in viral entry presumably play some role in self-protection. Like SCLC, PNECs can 300 switch from ASCL1+ to YAP1+ through Notch activation, but in the context of tissue repair (7). Our findings 301 suggest that the increase of cell autonomous immune gene expression as high NE-score SCLCs transition 302 to low NE-score SCLCs is mirroring the changes that normally take place during the transdifferentiation of 303 PNECs to other lung epithelial cell types, and in SCLC, this had in turn led to an increased tumor-immune 
305 between neuroendocrine and immune gene expression to other cancer types. For NBL, a cancer that had 306 not previously been classified based on NE properties, we were able to identify more inflammatory variant 307 tumors with loss of NE lineage gene expression. It would be interesting to explore more of such molecular 308 similarities between SCLC and other tumors with NE/neuronal lineage.

310 The full repertoire of immune evasion strategies employed by SCLC remains to be elucidated. However, our 311 results tying together with current clinical treatment findings raise several important questions and 312 paradoxes. The first paradox is that we found a depletion of immune infiltrates in high NE-score SCLC 313 tumors and other neuroendocrine tumors (NETs), associated with down regulation of MHC I expression. 314 While this MHC I expression explains the presence of very few T cells, it raises the question of how high 315 NE-score NETs evade natural killer cells that normally would recognize the "missing self" that such MHC I 316 expression loss conveys (61). Thus, we feel the high NE-score low-MHC I expression pairing indicates we need to understand how natural killer cell mechanisms are avoided in NET pathogenesis. The second 318 paradox is that low NE-score "variant" SCLCs appear to be associated with expression of MHC I and a 319 more immune infiltrated tumor microenvironment, yet clinical trials of immune checkpoint blockade do not 320 clearly show these are the tumors responding to such therapy. Since we found these tumors also express 321 many immunosuppressive genes it will be important to know which of these immunosuppressive gene 322 functions need to be targeted to achieve anti-tumor immune responses. Finally, we observed expression of $323 \mathrm{MHC}$ I in selected SCLC samples with chemoresistance and increased MYC expression even without 324 changes in ASCL1 expression. We need to know if immunosuppressive mechanisms are the same or 325 different in the high vs. low NE-score SCLC resistant to chemotherapy. We conclude, that some 30 years 326 after the first description of "classic" (high NE-score) and "variant" (low NE-score) SCLCs there are 327 important links between these NE phenotypes and the expression of immune phenotypes, and between 328 similar gene expression profiles of SCLC and pulmonary neuroendocrine cells. Importantly, these 329 correlations identify important problems to be solved of clinical therapeutic translational relevance. 


\begin{tabular}{|c|c|c|c|c|c|}
\hline Source & Name & Tissue Source & Sample Type & $\mathbf{n}$ & Reference \\
\hline Human & $\begin{array}{l}\text { SCLC cell lines/ } \\
\mathrm{NCl} / \text { Hamon Center }\end{array}$ & SCLC & Cell line & 69 & This study \\
\hline Human & Cañadas_2014 & SCLC & Cell line & 6 & (53) \\
\hline Human & Drapkin_2018 & SCLC & PDX & 19 & (54) \\
\hline Human & Rudin_2012 & SCLC & Tumor & 29 & (9) \\
\hline Human & George_2015 & SCLC & Tumor & 81 & (10) \\
\hline Human & Jiang_2016 & SCLC & Tumor & 79 & $(62)$ \\
\hline Human & $\begin{array}{l}\text { SCLC tumors } \\
\text { (this study) }\end{array}$ & SCLC & Tumor & 18 & This study \\
\hline Human & $\operatorname{expO}$ & Lung cancer & Tumor & 109 & (63) \\
\hline Human & Rousseaux_2013 & Lung cancer & Tumor & 286 & $(63,64)$ \\
\hline Human & CCLE & Pan-cancer & Cell line & - & $(25)$ \\
\hline Human & TCGA & Pan-cancer & Tumor & 10535 & (50) \\
\hline Human & TARGET & Pan-cancer & Tumor & 734 & (50) \\
\hline Mouse & Lim_2017 & SCLC & $\begin{array}{l}\text { Pooled FACS sorted } \\
\text { tumor cells }{ }^{\wedge}\end{array}$ & 6 & (18) \\
\hline Human & Travaglini_2020 & Healthy lung & Single cell & 9384* & (39) \\
\hline Mouse & Ouadah_2019 & Healthy lung & Single cell & $46^{*}$ & (7) \\
\hline
\end{tabular}

Table 1. Datasets used for analyses

PDX, Patient-deived Xenografts; FACS, Fluorescence-activated cell sorting; scRNA-seq, Single-cell RNA sequencing; * cells; - Note that CCLE datasets were used in multiple analyses with different numbers of

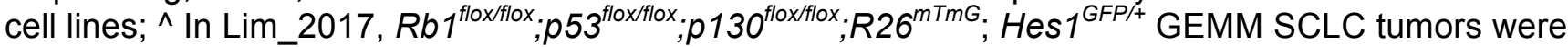
initiated by Ad-CMV-Cre, sorted by Tomato and GFP to obtain relatively pure tumor cells. 


\section{Figure 1 NE score and SCLC molecular subtypes}

335 a, Heatmaps visualizing expression of molecular subtype-specific TFs and NE scores. Two heatmaps were 336 generated for each study, with one ordered by complete linkage hierarchical clustering of TFs and the other 337 ordered by NE scores. b, Pairwise associations among NE scores and molecular subtype-specific TFs.

338 Lower left panels are scatter plots, diagonal line panels are density plots and upper right panel shows 339 correlation coefficients from pairwise Pearson correlation. ${ }^{*}$, p-value $<0.05 . \mathbf{c}, \mathrm{H} \& \mathrm{E}$ staining of two high NE340 score SCLC tumor samples showing classic SCLC morphology with dark nuclei, scant cytoplasm and 341 inconspicuous nucleoli. d, ASCL1 IHC staining and H\&E staining of a low NE-score SCLC tumor, showing 342 variable morphology at different selected areas, where ASCL1-low areas appear to be more variant-like e, 343 Quantifications of TF expression from IHC staining or microarray profiling, samples are ordered by 344 increasing NE scores. f, IHC of ASCL1, NEUROD1 and POU2F3 in two tumors that express both ASCL1 and NEUROD1. Two areas per tumor were selected for showing intratumoral heterogeneity in ASCL1 and NEUROD1 expression patterns.

\section{Figure 2 Repression of ISGs in high NE-score SCLC and PNECs}

349 a, GSEA enrichment plots for selected genesets. Results from SCLC cell lines, PDXs (Drapkin_2018) and 350 patient tumor datasets were superimposed. Normalized enrichment score (NES) were provided. *, multiple 351 comparison adjusted $p$-value $<0.05$. b, Heatmaps for top 25 leading edge genes selected from genesets in 352 (a). Gene expression matrix of each dataset was annotated with color-coded Pearson correlation coefficient 353 (from correlating NE score with gene expression) as a left-side column, and a top bar indicating NE scores.

354 c, Scatter plots showing negative correlation between NE score and Ser536 phosphorylation on NFkB-p65 355 in SCLC cell lines. Pearson correlation coefficient was provided. *, $p$-value $<0.05$. d, Heatmap showing 356 relative expression of selected lineage factors (ASCL1 and YAP1), REST targets and ISGs (same genes as 357 used in $\mathbf{b}$, determined from $\mathbf{a}$ ) as well as interferon receptor genes in healthy human lung epithelial cells 358 based on scRNA-seq experiments.

Figure 3 Low NE-score variant SCLC have increased tumor-immune interaction 
361 a, Expression of MHC I genes and pan-leukocyte marker PTPRC in lung tumors from the

362 "Rousseaux_2013" dataset. Box whisker plots are filled with color reflecting the median NE score in

363 different histological subtypes. Color for scatterplot symbols reflects NE score for different samples. b,

364 Heatmaps visualizing expression of MHC I genes across multiple SCLC datasets. c, Heatmaps visualizing 365 expression of PTPRC, immune-cell-type-specific signature scores, PD-1 blockade response-predicting IFN366 gamma related signature genes (46), immune checkpoint genes and suppressive cytokines and receptors in 367 SCLC tumor datasets.

Figure 4 Intertumoral and intratumoral heterogeneity in T cell infiltration from SCLC tumors with variable NE features

371 a, IHC of ASCL1, CD4 and CD8 in selected tumors. SCLC-04 is a SCLC tumor with NE score of 0.4. CD8 372 or CD4 T cells were few in the ASCL1-high regions but abundant in the ASCL1-low region; SCLC-20 is a 373 tumor with NE score of -0.05 , similar reciprocal relationship of ASCL1 staining and T cell infiltration was 374 observed. Representative regions with high or low ASCL1 staining were shown. b, Relationship between 375 IHC-determined per area CD4 and CD8 T cell count, gene expression-based T cell score and NE score in 376 all 9 tumors assessed. Scatter plots and Pearson correlation coefficients were provided for assessment of 377 pairwise correlations. * , Pearson correlation with $p$-value $<0.05$. c, Schematic diagram showing relationship 378 between neuroendocrine and immune gene expression in normal cells and neuroendocrine tumors (NETs).

380 Figure 5 Relationship between NE scores and immune phenotypes in pan-cancer samples $381 \mathbf{a}-\mathbf{b}$, NE scores of pan-cancer samples in the TARGET pediatric cancer cohorts (a) and TCGA adult cancer 382 cohorts (b). c, NE scores by immune subtype in TCGA pan-cancer samples. d, Relationship between NE 383 scores and tumor-infiltrating lymphocytes regional fraction or leukocyte fraction in TCGA pan-cancer 384 samples. e, Heatmap visualizing expression of various genes and summary scores previously assessed for 385 SCLC and now in NBL with cell line and tumor datasets side-by-side. f, Scatter plots showing negative 386 correlation between NE score and Ser536 phosphorylation on NFkB-p65 in NBL cell lines. Pearson correlation coefficient was provided. *, p-value $<0.05$. 
a, Heatmap visualizing increased expression of ISGs, MHC I genes as cells switch from Ascl1+ to Yap1+ in

391 SCLC GEMM tumors from the "Lim_2017". GFP was expressed from endogenous promoter of a Notch

392 target gene Hes1 in $R \mathrm{~b}^{-{ }^{-} /} / \mathrm{p} 53^{-{ }^{-} /} / \mathrm{p} 130^{-{ }_{-}}$(TKO) background. Using flow cytometry, the authors first sorted out

393 SCLC tumor cells and then further sorted by GFP to obtain relatively pure tumor cells with different Notch

394 activation status. Three biological replicates were each provided for GFP negative (Notch inactive, classic

395 high-NE) cells and GFP positive cells (Notch active, low-NE). b, Different morphology and culture

396 characteristics of adherent H69-AD and the parental H69. c, Dose response curves for Cisplatin and

397 Etoposide in the $\mathrm{H} 69$ cell line pair. Note that H69-AD, the adherent line, is more resistant with higher IC50s.

398 d, Expression changes of selected genes in: H69 cell line pair from this study, H69 and derived

399 mesenchymal H69M cell lines from “Canadas_2014" and autologous PDX samples before and after

400 chemotherapy from “Drapkin_2018”. PDX parameters: TTP, time to progression, defined by time to 2x initial

401 tumor volume; RESP, change in tumor volume between initial tumor volume and minimum of day 14-28.

402 Relapsed sample from MGH-1514 did not show increased chemoresistance based on the RESP and TTP

403 parameters. Note that unlike other heatmaps, due to the small number of samples in each dataset,

404 expression is not scaled by gene in this heatmap. e, qPCR measurement of normalized $A S C L 1, B 2 M$ and

405 PSMB8 expression in naïve parental and chemoresistant H1436 xenograft tumors.

406

407 SUPPLEMENTARY FIGURE LEGENDS

408 Figure S1 Gene ontology analyses of genes associated with NE scores in SCLC datasets

409 Treemaps summarizing enriched Biological Process GO terms, with reduced redundancy, for genes

410 associated with NE scores in SCLC tumor dataset "George_2015" (a and c) or in SCLC cell lines (b and d).

\section{Figure S2 Expression of SPARCS, parainflammation and SASP genes in SCLC datasets}

413 a, Heatmaps visualizing expression of selected immune gene sets in multiple SCLC datasets. These gene

414 sets were previously reported in different studies to express cell autonomously in cancer. Genes within each

415 gene set were ordered by correlation with NE score from meta-analysis of all datasets. Gene expression

416 matrix of each dataset was annotated with a left-side column with color-coded Pearson correlation 
417 coefficient (from correlating NE score with gene expression), and a top bar indicating NE scores. b, UpSet

418 plot showing gene counts in intersections of the three gene sets used in (a). SPARCS genes are genes with 419 stimulated 3 prime antisense retroviral coding sequences; these genes have been shown to activate IFN420 mediated innate immune pathways (35). Parainflammation genes are innate immunity genes that were 421 found to express in cancer (36). SASP genes are senescence-associated secretory phenotype genes (65). 422

\section{Figure S3 Repression of viral defense/hijacked genes in PNECs compared to other lung epithelial} 424 cell types

425 a, Violin plots showing expression of selected lineage factor (ASCL1 and YAP1) and ISGs (TLR3 and IFI44) 426 in healthy human lung epithelial cells based on scRNA-seq experiments from "Travaglini_2020". Note that 427 from research of Zika virus, TLR3 has been shown to mediate the deleterious effect of Zika virus through 428 disruption of neurogenesis (66). b, Scatter plot showing relationship among selected lineage factor genes 429 (Ascl1 and Yap1) and ISGs (Ly6e and Tmprss2) in scRNA-seq data ("Ouadah_2019") of lung epithelial cells 430 isolated from a mouse model genetically engineered to enable lineage tracing of PNECs. AT2 and ciliated 431 cells transdifferentiated from PNECs have lost expression of Ascl1 but upregulated Yap1, Ly6e and 432 Tmprss2. Note that from research of coronavirus, LY6E is implicated in viral defense (42) whereas 433 TMPRSS2 mediates viral entry (43).

Figure S4 Expression of MHC I gene is positively associated with pan-leukocyte marker CD45 436 (encoded by PTPRC) in lung tumors and SCLC tumors

437 a, Expression of MHC I genes and PTPRC in lung tumors from Expression Project for Oncology (expO). b, 438 Positive correlation between MHC I expression scores and PTPRC in SCLC tumors but not cell lines or 439 PDXs (“Drapkin_2018”). *, p-value <0.05.

441 Figure S5 Upregulation of immunosuppressive genes in low NE-score SCLC tumors

442 a, Correlation between CD274 (PD-L1) expression and NE score. Negative association was not observed in 443 SCLC cell line or PDX (“Drapkin_2018”) datasets but was observed in SCLC tumor datasets as well as NBL 444 cell line (CCLE_neuroblastoma) and tumor (TARGET_NB) datasets. *, Pearson correlation with p-value < 
445 0.05. b, Ridgeline plot showing distribution of Pearson correlation coefficients from correlating NE score to 446 expression of 995 immunosuppressive genes (47) in SCLC cell line, PDX and patient tumor datasets. With 447 meta-analysis in the four SCLC tumor datasets, 562 out of the 995 genes were found to have significant 448 correlation with NE score and about $80 \%$ of those are negative correlations.

450 Figure S6 Cancer type-specific association between NE score and immune cell fractions

451 Cancer type-specific scatter plots of NE scores with tumor-infiltrating lymphocytes regional fraction (a) or 452 leukocyte fraction (b) estimated by Thorsson, Gibbs, et al. (51) in TCGA samples.

453

454 Figure S7 Expression of MYC and MHC I genes (summarized as MHC I scores) in SCLC cell lines 455 derived from primary lung tumors and metastatic tumors.

456 a, Scatterplots of MHC I score and MYC expression in lung cancer cell lines by samples types and 457 anatomical sites of origin. b, MYC and MHC I gene expression score compared by anatomical site. For 458 each gene, $p$-values for pairwise comparisons were calculated based on two-sided t-test followed by 459 adjustment for multiple comparisons using the Bonferroni method.

\section{SUPPLEMENTARY TABLES}

463 Table S1 NE signature based on SCLC cell line RNA-seq data

464 Table S2 Patient characteristics, data availability and quantification of CD4 and CD8 T cells based on IHC 465 Table S3 Correlation between 995 immunosuppressive genes and NE scores from SCLC datasets

\section{METHODS}

468 Computation of NE score

469 The construction of the original NE signature has been described by Zhang, Girard et al.(22). In this study 470 this signature has been updated with expression data from RNA-seq experiments. A quantitative NE score 471 can be generated from this signature using the formula: NE score $=($ correl NE - correl non-NE)/2 where 472 correl NE (or non-NE) is the Pearson correlation between expression of the 50 genes in the test sample and 
473 expression of these genes in the NE (or non-NE) cell line group. This score has a range of -1 to +1 , where

474 a positive score predicts for NE while a negative score predicts for non-NE cell types. The higher the score 475 in absolute value, the better the prediction.

476

477 Pathway enrichment analysis with GO terms

478 Gene Ontology enRIchment anaLysis and visuaLizAtion tool (GOrilla (67), http://cbl-gorilla.cs.technion.ac.il/)

479 was used to identify enriched GO terms (68) related to biological processes (BP) from gene lists ranked by

480 increasing or decreasing Pearson correlation with NE scores in cell line datasets or "George_2015" tumor

481 dataset. P-value threshold was set at $10^{\wedge}-3$ for resulting GO terms. The output was visualized by Treemap 482 R scripts generated from "reduce + visualize gene ontology" (REViGO (69), http://revigo.irb.hr/) and further 483 customized with modified color scheme.

484

485 Gene Set Enrichment Analysis (GSEA)

486 Gene set libraries were downloaded from Enrichr (24) (https://amp.pharm.mssm.edu/Enrichr/). Fast GSEA 487 based on gene label permutation from R package "fgsea" (70) was first used for a fast screening across a 488 large number of gene set libraries. After reviewing the results for SCLC cell lines, sample label permutation489 based GSEA (23) was run for selected gene set libraries to obtain normalized enrichment scores and 490 multiple comparison adjusted p-values. Pearson correlation was used as the ranking metric from correlating 491 gene expression with NE scores.

492

493 Visualization

494 All heatmaps were generated by R package "ComplexHeatmap"(71). Other R packages used for 495 visualization include "ggplot2" (72), "ggridges" (73), "ggrepel" (74), "ggpubr" (75), "treemap" (76), 496 "RColorBrewer" (77), "jcolors" (78) and "patchwork" (79).

\section{Expression data}

499 . Drapkin_2018 (54) was downloaded from GEO with accession id GSE110853; Rudin_2012 (9) was 500 obtained from the authors; George_2015 (10) was obtained from a supplementary table of the original 
501 publication; Jiang_2016 (62) was downloaded from GEO with accession id GSE60052; IGC's Expression

502 Project for Oncology - expO (GSE2109) and Rousseaux_2013 (GSE30219) (64) was processed

503 previously for the lung cancer explorer (LCE) (63). Pan-cancer data from TCGA and TARGET was

504 downloaded from Toil xena hub (50). For data from GEO, R package GEOquery (80) was used for

505 extracting the expression and phenotype data. Quantile normalization was performed for bulk expression

506 data by running the "normalize.quantiles" function from R package "preprocessCore" (81). Library size

507 normalization was performed for author-processed scRNA-seq data by running the "library.size.normalize"

508 function from R package "phateR" (82). Travaglini_2020 (39) was downloaded from Synapse with

509 accession id syn21041850. FACS-sorted SmartSeq2 data was used. Cell types with less than 10 cells were 510 removed from analyses.

\section{Gene Signatures}

513 SPARCS gene set is from a study by Cañadas et al (Figure $1 \mathrm{~S}$ in original article) (35). Parainflammation 514 gene set is from a study by Aran et al (Figure 1C in original article) (36). SASP gene set is from a study by 515 Ruscetti et al (Figure 2C in original article) (65).

516

517 Gene set "REST ENCODE" is from the "ENCODE_and_ChEA_Consensus_TFs_from_ChIP-X" library; and 518 "IFNA-BT2" and "IFNG-BT2" are from the "LINCS_L1000_Ligand_Perturbations_up" library. Both libraries were downloaded from Enrichr (24). Top 25 genes from leading edge and are common to all SCLC datasets 520 were selected for heatmap visualization. For ISGs, the leading edge genes from "IFNA-BT2" and "IFNG521 BT2" were first combined and then the top 25 genes were selected.

522

523 Mouse ISGs, from Cilloniz et al. (83), was identified from interferome (84) by specifying "mouse" as the 524 species of interest and "lung" as the organ of interest. An unfiltered ISG set was used for Figure 6A.

526 Human $\mathrm{MHC}$ I gene set is a combination of genes under GO terms

527 "GO_MHC_CLASS_I_PROTEIN_COMPLEX" and "GO_MHC_CLASS_I_PEPTIDE_LOADING_COMPLEX" 528 from Molecular Signatures Database (MSigDB) $(23,85)$. Mouse MHC I genes were selected from GO: 
529 0019885, "antigen processing and presentation of endogenous peptide antigen via MHC class I" based on

530 the Mouse Genome Informatics (MGI) database (86). Immune-cell-specific gene sets in human are from

531 DisHet (45). Interferon-gamma signature that predicts response to PD-1 blockade is from Ayers et al. (46).

532 The 21-gene immune checkpoint set and 995-gene immunosuppressive set are from HisgAtlas, a human 533 immunosuppression gene database (47).

534

$535 \quad$ MHC I and Immune infiltrate scores

536 R package GSVA (87) was used to compute immune infiltrate scores by single sample GSEA (ssGSEA) 537 method $(23,44)$.

538

539 Patients and tissue specimens

540 Study participants included 18 patients who were diagnosis with SCLC and underwent surgical resection of 541 lung cancer between 2006 and 2010 at the Department of Lung Cancer Surgery, Tianjin Medical University 542 General Hospital. Written informed consent was obtained, and the institutional ethics committee of Tianjin 543 Medical University General Hospital approved the study. The cases were selected based on the following 544 criteria: (1) diagnosis of primary lung cancer clinical stage I to IV (pTNM); (2) undergoing surgical resection.

545 Pathologic diagnosis was based on WHO criteria. Lung cancer staging for each patient was performed 546 according to the AJCC Cancer Staging Manual, 8th edition, and was based on findings from physical 547 examination, surgical resection, and computed tomography of the chest, abdomen, pelvis, and brain. The 548 following information was collected from the patients' medical records: age, gender, clinical stage, 549 pathologic diagnosis, differentiation, lymph node status, metastasis, smoking status, and overall survival 550 time. Resected lung and lymph node tissues were immediately immersed in liquid nitrogen until RNA 551 extraction.

552

553 Immunohistochemistry - histology and immunohistochemistry

554 Tissue blocks, once collected, were reviewed by staff thoracic pathologist to confirm SCLC histology.

555 Consecutive four-micrometer-thick tissue sections were cut for immunohistochemistry. IHC staining was 556 performed with a Bond Max automated staining system (Leica Microsystems Inc., Vista, CA) using IHC 
557 parameters optimized previously. Antibodies used in this study included ASCL1 (dilution 1:25; Clone 558 24B72D11.1, BD Biosciences, Catalog \# 556604), NEUROD1 (dilution 1:100; Clone EPR20766, Abcam, 559 ab213725), POU2F3 (dilution 1:200; polyclonal, Novus Biologicals, NBP1-83966), CD4 (dilution 1:80; Leica 560 Biosystems, CD4-368-L-CE-H) and CD8 (dilution 1:25; Thermo Scientific, MS-457s) in a Leica Bond Max 561 automated stainer (Leica Biosystems Nussloch $\mathrm{GmbH}$ ). The expression of proteins was detected using the 562 Bond Polymer Refine Detection kit (Leica Biosystems, Cat\# DS9800) with diaminobenzidine as chromogen 563 (88). The slides were counterstained with hematoxylin, dehydrated and cover-slipped. FFPE cell lines 564 pellets with known expression of ASCL1, NEUROD1 and POU2F3 were used to establish and optimize IHC 565 conditions and assess sensitivity and specificity for each antibody.

566

567 Immunohistochemistry - Image analysis

568 The stained slides were digitally scanned using the Aperio ScanScope Turbo slide scanner (Leica 569 Microsystems Inc.) under $\times 200$ magnification. The images were visualized by ImageScope software (Leica 570 Microsystems, Inc.) and analyzed using the Aperio Image Toolbox (Leica Microsystems Inc.). Different 571 intensity levels of ASCL1, NEUROD1 or POU2F3 nuclear expression were quantified using a 4-value 572 intensity score $(0$, none; 1 , weak; 2 , moderate; and 3 , strong) and the percentage $(0-100 \%)$ of the extent of 573 reactivity. A final expression score ( $\mathrm{H}$-score) was obtained by multiplying the intensity and reactivity 574 extension values (range, 0-300) as previously described (89).

575 The lymphocyte cells expressing CD4+ and CD8+ were counted by a pathologist using Aperio Image 576 Toolbox analysis software (Aperio, Leica Biosystems) and expressed as cell density (CD4+ and CD8+ 577 cells $/ \mathrm{mm}^{2}$ of analyzed tissue) $(88,90)$.

\section{Microarray Assay}

580 The Human Genome U133 Plus 2.0 microarray with 54,000 probe sets was purchased from the Affymetrix 581 (Lot \#: 4032359). Total RNA was extracted with the Trizol reagent (Invitrogen) from the tissue samples. The 582 extracted RNA was purified using the Oligotex mRNA Midi kit (Qiagen). Then double-strand cDNA synthesis 583 was made using one-cycle cDNA synthesis kit (Affymetrix) and purified again by column followed by the 584 synthesis of complementary RNA (cRNA) with in vitro transcription (IVT) kit (Affymetrix). The cRNA was 
585 fragmented after purification by column and the quality was verified by ultraviolet spectrophotometer and

$5861.2 \%$ denaturing agarose gel. After the test gene-chip (Lot\#: 4020852, Affymetrix) was affirmed satisfactory 587 the real chip hybridization of cRNA fragmentation was performed and then stained and washed. Finally the 588 real chip was scanned in Affymetrix scanner and the data was collected by GCOS (gene-chip operation 589 software). CEL files were read into an AffyBatch object by "AffyBatch" function under the "affy" (91) R 590 package. Alternative cdf package (92) "hgu133plus2hsentrezg" was downloaded from 591 "http://mbni.org/customcdf/22.0.0/entrezg.download/hgu133plus2hsentrezg.db_22.0.0.zip" and was 592 specified in the function so that the resulting expression data was processed to gene level rather than the 593 original probe level. (Probe name follows format concatenating Entrez ID for the gene and "_at". For 594 example "3939_at" corresponds to gene $L D H A)$. The AffyBatch object was then converted to an expression set using robust multi-array average (RMA) expression measure by running the "rma" function under $R$ 596 package "affy". Quantile normalization was performed by running "normalize.quantiles" function from R package "preprocessCore" (81)

598

599

RNA-seq

600 RNA samples from SCLC cell lines $(n=69)$ were prepared at UT Southwestern (Dallas TX) and sent to 601 Baylor College of Medicine (David Wheeler, Houston TX) for paired-end RNA sequencing. Analysis was 602 then performed at UT Southwestern: Reads were aligned to the human reference genome GRCh38 using 603 STAR-2.7(93) (https://github.com/alexdobin/STAR) and FPKM values were generated with cufflinks-2.2.1 604 (94) (http://cole-trapnell-lab.github.io/cufflinks/). All data were then pooled, upper-quartile normalized (95), 605 and log-transformed.

607 Cell culture

608 All SCLC cell lines used in these studies were originally established in the John D. Minna and Adi F. Gazdar 609 laboratories. The cultured Small Cell Lung Cancer (SCLC) cell lines were obtained from both the National 610 Cancer Institute (NCI) and Hamon Cancer Center (HCC) libraries. Cells were cultured in RPMI-1640 media 611 (Sigma Life Science, St. Louis, MO) supplemented with 5\% Fetal Bovine Serum (FBS). RPMI-1640 612 supplemented with 5\% FBS will be referred to as R5. All cells were incubated in NuAire (NuAire, Plymouth, 
$613 \mathrm{MN}$ ) humidified incubators at $37^{\circ} \mathrm{C}$ at $5 \% \mathrm{CO} 2$. All cell lines were regularly tested for mycoplasma

614 contamination (Bulldog Bio, Portsmouth, $\mathrm{NH}$ ) and fingerprinted using a PowerPlex 1.2 kit (Promega,

615 Madison, WI) to confirm the cell line identity.

616

617 Establishing adherent $\mathrm{H} 69$ (H69-AD)

618 The early passage of parental $\mathrm{H} 69$ cell line grew as a mixture of floating and adherent cells. To enrich for adherent cells, the floating population of $\mathrm{H} 69$ was washed off during growth media replacement and fresh media was provided for expansion of the remaining adherent cells. This was repeated until every passage grew as adherent cells with few to no suspension cells. This derived adherent subline was designated as H69-AD.

Drug response assay

625 Cisplatin and Etoposide were obtained from Selleck Chemicals LLC, USA. 5,000 cells of H69 and H69-AD were cultured in 100 uL R5 growth media per well in ultra-low adherent, clear, round bottom, 96 well plates (BD Biosciences, USA) for 48 hours. An additional $100 \mu \mathrm{l}$ R5 plus either a control (DMSO) or drug was added to the plate. 96 hours after drug treatment, each cell line was assayed using the Cell-Titer-Glo reagent (Promega, Inc.). The fluorescence intensity was recorded at $570 \mathrm{nM}$. A standard 4-parameter log630 logistic fit between the survival rate and the dosage was generated by the "drm" function from the $R$ 631 package "drc"(96).

633 Xenograft models for parental and chemoresistant SCLC tumors

634 Subcutaneous xenograft in NSG mice was derived from direct implantation of untreated H1436 cells or re635 implantation of chemoresistant tumors after 4 cycles of Cisplatin and Etoposide (EC), or plus 4 cycles of 636 Cisplatin (reduced from EC due to toxicity). Specifically, a million H1436 cells were resuspended in $100 \mu \mathrm{l}$ 637 mixture of serum-free RPMI 1640 and Matrigel (BD Bioscience \#356237) at 1:1 ratio and immediately 638 injected in the flank of 6-8-week-old female NSG mouse (Jackson Laboratory \#005557). Mice were 639 randomized after tumor cell injection. Treatment starts after a week when the tumor becomes palpable. 5 mg/kg/w Cisplatin (Sigma P4394) in saline, 10 mg/kg/w Etoposide (Sigma E1383) in 30\% PEG 300 (Sigma 
641 202371) were freshly prepared and administered by intraperitoneal injection, for 4 cycles in total to obtain

642 the first group of chemoresistant tumors. An additional 4 cycles of Cisplatin were administered in a second

643 group of mice to obtain tumors with further potentiated chemoresistance. To harvest the tumor, $10 \mathrm{ml}$

644 digestion media was used per mouse. This was prepared freshly by supplementing $9 \mathrm{ml}$ HBSS with $1 \mathrm{ml}$

645 type IV collagenase, $50 \mu \mathrm{I}$ DNase II and $50 \mu \mathrm{l} 1 \mathrm{M} \mathrm{CaCl}_{2}$. Tumors were collected and placed in HBSS

646 immediately following dissection. A fraction of the tumor was cut into a few pieces and flash-frozen in liquid

647 nitrogen to be saved in aliquots for molecular assays. The remaining chunk was finely minced with a sterile

648 scalpel blade. For re-implantation, the minced tissue was resuspended in digestion media, rotated at $37^{\circ} \mathrm{C}$

649 for $20 \mathrm{~min}$, filtered through a $40 \mu \mathrm{m}$ filter, centrifuged at $300 \mathrm{x} \mathrm{g}$ for $5 \mathrm{~min}$.

650

651 Quantitative reverse transcription PCR

$652 \sim 20 \mathrm{mg}$ flash-frozen tumor fragments were weighed out and homogenized in $1 \mathrm{ml}$ TRIzol (Invitrogen 653 \#15596-026) in Precellys tissue homogenizing mixed beads kit (Cayman Chemical \#10409). $0.2 \mathrm{ml}$ 654 chloroform (Fisher \#S25248) was added to the TRIzol lysate and the mixture was vortexed for $10 \mathrm{~s}$ and 655 centrifuged at $12,000 \times \mathrm{g}$ for $15 \mathrm{~min}$ at $4{ }^{\circ} \mathrm{C}$ for phase separation. $450 \mathrm{ul}$ aqueous phase was collected, 656 mixed well with $0.5 \mathrm{ml}$ isopropanol (Fisher \#A451-1) and precipitated RNA was collected by centrifugation at $65712,000 \times \mathrm{g}$ for $10 \mathrm{~min}$ at $4{ }^{\circ} \mathrm{C}$, The RNA pellet was rinsed in $1 \mathrm{ml} 75 \%$ ethanol, then dissolved in $100 \mu \mathrm{l}$ 658 deionized water by incubating at $55^{\circ} \mathrm{C}$ for $5 \mathrm{~min} .500 \mathrm{ng}$ total RNA was reverse-transcribed to cDNA in a 20 $659 \mu \mathrm{l}$ reaction with $4 \mu \mathrm{l}$ iScript reverse transcription supermix (Bio-Rad \#1708841) at $25^{\circ} \mathrm{C}$ for $5 \mathrm{~min}, 46{ }^{\circ} \mathrm{C}$ for $66020 \mathrm{~min}$, and $95^{\circ} \mathrm{C}$ for $1 \mathrm{~min}$. The mixture was then 1:5 diluted with deionized water. Target sequences in 661 cDNA library were amplified in $10 \mu$ qPCR reaction (5 $\mu$ I SYBR Green supermix (Bio-Rad \#1725121), 0.675 $662 \mu \mathrm{l} 2.5 \mu \mathrm{M}$ primer mix and $0.45 \mu \mathrm{l}$ diluted cDNA) at $95{ }^{\circ} \mathrm{C} 10 \mathrm{~s}, 60^{\circ} \mathrm{C} 30 \mathrm{~s}$, for 40 cycles. All procedures were 663 performed under RNase-free condition unless specified. For data analysis, median was taken from 664 triplicates, normalized by Ct values of control gene PPIA, exponentiated with base 2 then divided by the 665 median of parental samples.

666

667 Study Approval 
668 The protocol of collecting human SCLC tumor tissue for research was approved by the Ethics Committee of

669 Tianjin Medical University General Hospital. Written informed consent was received from participants prior

670 to inclusion in the study. Specimen collection did not interfere with standard diagnostic and therapeutic

671 procedures. All mouse procedures were performed with the approval of the University of Texas

672 Southwestern Medical Center IACUC.

673

674 Data availability

675 Scripts used for this manuscript are available upon request. The RNA-seq gene expression data from 676 UTSW SCLC has been added to dbGaP (accession phs001823.v1.p1) (97). SCLC tumor microarray data 677 used in this study has been deposited to GEO with accession id GSE149507.

678

679

\section{ACKNOWLEDGEMENT}

680

Support for this work comes from the National Institutes of Health [1R35GM136375, 5P30CA142543, 5U01CA213338-04, 3P50CA070907, and R01GM115473], and the Cancer Prevention Research Institute of 682 Texas [RP180805]. We dedicate this work to Dr. Adi F. Gazdar, who had initially conceptualized and led this 683 project until his passing in December 2018. We thank Ms. Jessie Norris for proofreading the manuscript.

684

\section{AUTHOR CONTRIBUTIONS}

686 Conception and design, A.F.G. and L.C.; Development of methodology, L.C., L.G. and T.W.; Acquisition of 687 data, L.C., H.L., F.H., J.F., L.G., J.C., Y.L., Y.Z., D.D., V.S., C.S.K., C.Y., A.A., K.H., M.P. and B.D.; 688 Analysis and interpretation of data, L.C., J.F., G.J., L.Y. and W.Z.; Writing, review and/or revision of the 689 manuscript, L.C., H.L., E.A., R.J.D and J.D.M.; Study supervision, D.S.S., I.I.W., G.X., J.D.M., Y.X. and 690 A.F.G.

691

692 COMPETING INTERESTS

693 J.D.M. receives licensing fees from the $\mathrm{NCl}$ and UT Southwestern to distribute cell lines. R.J.D is on the 694 advisory board for Agios Pharmaceuticals. D.S.S and W.Z. are currently employed by Genentech Inc. and 695 own stock in Roche Holdings. I.I.W is speaker at Medscape, MSD, Genentech/Roche, PlatformQ Health, 
Pfizer, AstraZeneca, Merck; receives research support from Genentech, Oncoplex, HTG Molecular,

697 DepArray, Merck, Bristol-Myers Squibb, Medimmune, Adaptive, Adaptimmune, EMD Serono, Pfizer,

698 Takeda, Amgen, Karus, Johnson \& Johnson, Bayer, lovance, 4D, Novartis, and Akoya; and is on the

699 advisory boards for Genentech/Roche, Bayer, Bristol-Myers Squibb, AstraZeneca/Medimmune, Pfizer, HTG

700 Molecular, Asuragen, Merck, GlaxoSmithKline, Guardant Health, Oncocyte, and MSD.

701

\section{REFERENCE}

703 1. Gazdar AF, Bunn PA, Minna JD. Small-cell lung cancer: what we know, what we need to know

704

705

706

707

708

709

710

711

712

713

714

715

716

717

718

719

720

721

722

723

724

725

726

727

728

729

730

731

732

733

734

735

736

737

738

739 10.1038/nrc.2017.106. PubMed PMID: 29123245.

2. $\quad$ H.R.733 UC. Recalcitrant Cancer Research Act of 2012 2012. Available from: https://www.congress.gov/bill/112th-congress/house-bill/733.

3. Travis WD, Brambilla E, Nicholson AG, Yatabe Y, Austin JHM, Beasley MB, Chirieac LR, Dacic S, Duhig E, Flieder DB, Geisinger K, Hirsch FR, Ishikawa Y, Kerr KM, Noguchi M, Pelosi G, Powell CA, Tsao MS, Wistuba I, Panel WHO. The 2015 World Health Organization Classification of Lung Tumors: Impact of Genetic, Clinical and Radiologic Advances Since the 2004 Classification. J Thorac Oncol. 2015;10(9):1243-60. Epub 2015/08/21. doi: 10.1097/JT0.0000000000000630. PubMed PMID: 26291008.

4. Augustyn A, Borromeo M, Wang T, Fujimoto J, Shao C, Dospoy PD, Lee V, Tan C, Sullivan JP, Larsen JE, Girard L, Behrens C, Wistuba, II, Xie Y, Cobb MH, Gazdar AF, Johnson JE, Minna JD. ASCL1 is a lineage oncogene providing therapeutic targets for high-grade neuroendocrine lung cancers. Proc Natl Acad Sci U S A. 2014;111(41):14788-93. Epub 2014/10/01. doi: 10.1073/pnas.1410419111. PubMed PMID: 25267614; PMCID: PMC4205603.

5. Borges M, Linnoila RI, van de Velde HJ, Chen H, Nelkin BD, Mabry M, Baylin SB, Ball DW. An achaete-scute homologue essential for neuroendocrine differentiation in the lung. Nature. 1997;386(6627):852-5. Epub 1997/04/24. doi: 10.1038/386852a0. PubMed PMID: 9126746.

6. Boers JE, den Brok JL, Koudstaal J, Arends JW, Thunnissen FB. Number and proliferation of neuroendocrine cells in normal human airway epithelium. Am J Respir Crit Care Med. 1996;154(3 Pt 1):758-63. Epub 1996/09/01. doi: 10.1164/ajrccm.154.3.8810616. PubMed PMID: 8810616.

7. Ouadah Y, Rojas ER, Riordan DP, Capostagno S, Kuo CS, Krasnow MA. Rare Pulmonary Neuroendocrine Cells Are Stem Cells Regulated by Rb, p53, and Notch. Cell. 2019;179(2):403-16 e23. Epub 2019/10/05. doi: 10.1016/j.cell.2019.09.010. PubMed PMID: 31585080; PMCID: PMC6782070. 8. Pleasance ED, Stephens PJ, O'Meara S, McBride DJ, Meynert A, Jones D, Lin ML, Beare D, Lau KW, Greenman C, Varela I, Nik-Zainal S, Davies HR, Ordonez GR, Mudie LJ, Latimer C, Edkins S, Stebbings L, Chen L, Jia M, Leroy C, Marshall J, Menzies A, Butler A, Teague JW, Mangion J, Sun YA, McLaughlin SF, Peckham HE, Tsung EF, Costa GL, Lee CC, Minna JD, Gazdar A, Birney E, Rhodes MD, McKernan KJ, Stratton MR, Futreal PA, Campbell PJ. A small-cell lung cancer genome with complex signatures of tobacco exposure. Nature. 2010;463(7278):184-90. Epub 2009/12/18. doi: 10.1038/nature08629. PubMed PMID: 20016488; PMCID: PMC2880489.

9. Rudin CM, Durinck S, Stawiski EW, Poirier JT, Modrusan Z, Shames DS, Bergbower EA, Guan Y, Shin J, Guillory J, Rivers CS, Foo CK, Bhatt D, Stinson J, Gnad F, Haverty PM, Gentleman R, Chaudhuri S, Janakiraman V, Jaiswal BS, Parikh C, Yuan W, Zhang Z, Koeppen H, Wu TD, Stern HM, Yauch RL, Huffman KE, Paskulin DD, Illei PB, Varella-Garcia M, Gazdar AF, de Sauvage FJ, Bourgon R, Minna JD, Brock MV, Seshagiri S. Comprehensive genomic analysis identifies SOX2 as a frequently amplified gene 
in small-cell lung cancer. Nat Genet. 2012;44(10):1111-6. Epub 2012/09/04. doi: 10.1038/ng.2405. PubMed PMID: 22941189; PMCID: PMC3557461.

742 10. George J, Lim JS, Jang SJ, Cun Y, Ozretic L, Kong G, Leenders F, Lu X, Fernandez-Cuesta L, Bosco G, Muller C, Dahmen I, Jahchan NS, Park KS, Yang D, Karnezis AN, Vaka D, Torres A, Wang MS, Korbel JO, Menon R, Chun SM, Kim D, Wilkerson M, Hayes N, Engelmann D, Putzer B, Bos M, Michels S, Vlasic I, Seidel D, Pinther B, Schaub P, Becker C, Altmuller J, Yokota J, Kohno T, Iwakawa R, Tsuta K, Noguchi M, Muley T, Hoffmann H, Schnabel PA, Petersen I, Chen Y, Soltermann A, Tischler V, Choi CM, Kim YH, Massion PP, Zou Y, Jovanovic D, Kontic M, Wright GM, Russell PA, Solomon B, Koch I, Lindner M, Muscarella LA, la Torre A, Field JK, Jakopovic M, Knezevic J, Castanos-Velez E, Roz L, Pastorino U, Brustugun OT, Lund-Iversen M, Thunnissen E, Kohler J, Schuler M, Botling J, Sandelin M, SanchezCespedes M, Salvesen HB, Achter V, Lang U, Bogus M, Schneider PM, Zander T, Ansen S, Hallek M, Wolf J, Vingron M, Yatabe Y, Travis WD, Nurnberg P, Reinhardt C, Perner S, Heukamp L, Buttner R, Haas SA, Brambilla E, Peifer M, Sage J, Thomas RK. Comprehensive genomic profiles of small cell lung cancer. Nature. 2015;524(7563):47-53. Epub 2015/07/15. doi: 10.1038/nature14664. PubMed PMID: 26168399; PMCID: PMC4861069.

\section{Doyle A, Martin WJ, Funa K, Gazdar A, Carney D, Martin SE, Linnoila I, Cuttitta F, Mulshine J,} Bunn P, et al. Markedly decreased expression of class I histocompatibility antigens, protein, and mRNA in human small-cell lung cancer. J Exp Med. 1985;161(5):1135-51. Epub 1985/05/01. doi: 10.1084/jem.161.5.1135. PubMed PMID: 2580935; PMCID: PMC2187608.

12. Burr ML, Sparbier CE, Chan KL, Chan YC, Kersbergen A, Lam EYN, Azidis-Yates E, Vassiliadis D, Bell CC, Gilan O, Jackson S, Tan L, Wong SQ, Hollizeck S, Michalak EM, Siddle HV, McCabe MT, Prinjha RK, Guerra GR, Solomon BJ, Sandhu S, Dawson SJ, Beavis PA, Tothill RW, Cullinane C, Lehner PJ, Sutherland KD, Dawson MA. An Evolutionarily Conserved Function of Polycomb Silences the MHC Class I Antigen Presentation Pathway and Enables Immune Evasion in Cancer. Cancer Cell. 2019;36(4):385-401 e8. Epub 2019/10/01. doi: 10.1016/j.ccell.2019.08.008. PubMed PMID: 31564637; PMCID: PMC6876280.

13. Yarchoan M, Hopkins A, Jaffee EM. Tumor Mutational Burden and Response Rate to PD-1 Inhibition. N Engl J Med. 2017;377(25):2500-1. Epub 2017/12/21. doi: 10.1056/NEJMc1713444. PubMed PMID: 29262275; PMCID: PMC6549688.

769 14. Iams WT, Porter J, Horn L. Immunotherapeutic approaches for small-cell lung cancer. Nat Rev

15. Gazdar AF, Carney DN, Nau MM, Minna JD. Characterization of variant subclasses of cell lines derived from small cell lung cancer having distinctive biochemical, morphological, and growth properties. Cancer Res. 1985;45(6):2924-30. Epub 1985/06/01. PubMed PMID: 2985258.

16. Carney DN, Gazdar AF, Bepler G, Guccion JG, Marangos PJ, Moody TW, Zweig MH, Minna JD. Establishment and identification of small cell lung cancer cell lines having classic and variant features. Cancer Res. 1985;45(6):2913-23. Epub 1985/06/01. PubMed PMID: 2985257.

17. Johnson BE, Russell E, Simmons AM, Phelps R, Steinberg SM, Ihde DC, Gazdar AF. MYC family DNA amplification in 126 tumor cell lines from patients with small cell lung cancer. J Cell Biochem Suppl. 1996;24:210-7. Epub 1996/01/01. doi: 10.1002/jcb.240630516. PubMed PMID: 8806103. 18. Lim JS, Ibaseta A, Fischer MM, Cancilla B, O'Young G, Cristea S, Luca VC, Yang D, Jahchan NS, Hamard C, Antoine M, Wislez M, Kong C, Cain J, Liu YW, Kapoun AM, Garcia KC, Hoey T, Murriel CL, Sage J. Intratumoural heterogeneity generated by Notch signalling promotes small-cell lung cancer. Nature. 2017;545(7654):360-4. Epub 2017/05/11. doi: 10.1038/nature22323. PubMed PMID: 28489825; PMCID: PMC5776014.

19. Gazdar AF, Bunn PA, Minna JD. Small-cell lung cancer: what we know, what we need to know and the path forward. Nat Rev Cancer. 2017;17(12):725-37. doi: 10.1038/nrc.2017.87. PubMed PMID: 29077690.

20. Rudin CM, Poirier JT, Byers LA, Dive C, Dowlati A, George J, Heymach JV, Johnson JE, Lehman JM, MacPherson D, Massion PP, Minna JD, Oliver TG, Quaranta V, Sage J, Thomas RK, Vakoc CR, Gazdar AF. 
Molecular subtypes of small cell lung cancer: a synthesis of human and mouse model data. Nat Rev

Cancer. 2019;19(5):289-97. Epub 2019/03/31. doi: 10.1038/s41568-019-0133-9. PubMed PMID: 30926931; PMCID: PMC6538259.

21. Gazdar AF. Morphologic and Other Forms of Heterogeneity in Small Cell Lung Cancer: What Can We Learn from Them? J Thorac Oncol. 2018;13(2):148-50. Epub 2018/02/10. doi: 10.1016/j.jtho.2017.11.004. PubMed PMID: 29425612.

22. Zhang W, Girard L, Zhang YA, Haruki T, Papari-Zareei M, Stastny V, Ghayee HK, Pacak K, Oliver TG, Minna JD, Gazdar AF. Small cell lung cancer tumors and preclinical models display heterogeneity of neuroendocrine phenotypes. Transl Lung Cancer Res. 2018;7(1):32-49. Epub 2018/03/15. doi: 10.21037/tlcr.2018.02.02. PubMed PMID: 29535911; PMCID: PMC5835590.

23. Subramanian A, Tamayo P, Mootha VK, Mukherjee S, Ebert BL, Gillette MA, Paulovich A, Pomeroy SL, Golub TR, Lander ES, Mesirov JP. Gene set enrichment analysis: a knowledge-based approach for interpreting genome-wide expression profiles. Proc Natl Acad Sci U S A. 2005;102(43):15545-50. Epub 2005/10/04. doi: 10.1073/pnas.0506580102. PubMed PMID: 16199517; PMCID: PMC1239896.

24. Kuleshov MV, Jones MR, Rouillard AD, Fernandez NF, Duan Q, Wang Z, Koplev S, Jenkins SL, Jagodnik KM, Lachmann A, McDermott MG, Monteiro CD, Gundersen GW, Ma'ayan A. Enrichr: a comprehensive gene set enrichment analysis web server 2016 update. Nucleic Acids Res. 2016;44(W1):W90-7. Epub 2016/05/05. doi: 10.1093/nar/gkw377. PubMed PMID: 27141961; PMCID: PMC4987924.

25. Ghandi M, Huang FW, Jane-Valbuena J, Kryukov GV, Lo CC, McDonald ER, 3rd, Barretina J, Gelfand ET, Bielski CM, Li H, Hu K, Andreev-Drakhlin AY, Kim J, Hess JM, Haas BJ, Aguet F, Weir BA, Rothberg MV, Paolella BR, Lawrence MS, Akbani R, Lu Y, Tiv HL, Gokhale PC, de Weck A, Mansour AA, Oh C, Shih J, Hadi K, Rosen Y, Bistline J, Venkatesan K, Reddy A, Sonkin D, Liu M, Lehar J, Korn JM, Porter DA, Jones MD, Golji J, Caponigro G, Taylor JE, Dunning CM, Creech AL, Warren AC, McFarland JM, Zamanighomi M, Kauffmann A, Stransky N, Imielinski M, Maruvka YE, Cherniack AD, Tsherniak A, Vazquez F, Jaffe JD, Lane AA, Weinstock DM, Johannessen CM, Morrissey MP, Stegmeier F, Schlegel R, Hahn WC, Getz G, Mills GB, Boehm JS, Golub TR, Garraway LA, Sellers WR. Next-generation characterization of the Cancer Cell Line Encyclopedia. Nature. 2019;569(7757):503-8. doi: 10.1038/s41586-019-1186-3. PubMed PMID: 31068700.

26. Sakurai H, Chiba H, Miyoshi H, Sugita T, Toriumi W. IkappaB kinases phosphorylate NF-kappaB p65 subunit on serine 536 in the transactivation domain. J Biol Chem. 1999;274(43):30353-6. Epub 1999/10/16. doi: 10.1074/jbc.274.43.30353. PubMed PMID: 10521409.

27. Dinarello CA. Interleukin-18, a proinflammatory cytokine. Eur Cytokine Netw. 2000;11(3):4836. Epub 2001/02/24. PubMed PMID: 11203186.

28. Cornelissen C, Luscher-Firzlaff J, Baron JM, Luscher B. Signaling by IL-31 and functional consequences. Eur J Cell Biol. 2012;91(6-7):552-66. Epub 2011/10/11. doi: 10.1016/j.ejcb.2011.07.006. PubMed PMID: 21982586.

29. Kordass T, Osen W, Eichmuller SB. Controlling the Immune Suppressor: Transcription Factors and MicroRNAs Regulating CD73/NT5E. Front Immunol. 2018;9:813. Epub 2018/05/04. doi: 10.3389/fimmu.2018.00813. PubMed PMID: 29720980; PMCID: PMC5915482.

30. Yang L, Pang Y, Moses HL. TGF-beta and immune cells: an important regulatory axis in the tumor microenvironment and progression. Trends Immunol. 2010;31(6):220-7. Epub 2010/06/12. doi: 10.1016/j.it.2010.04.002. PubMed PMID: 20538542; PMCID: PMC2891151.

31. D'Acquisto F, Perretti M, Flower RJ. Annexin-A1: a pivotal regulator of the innate and adaptive immune systems. Br J Pharmacol. 2008;155(2):152-69. Epub 2008/07/22. doi: 10.1038/bjp.2008.252. PubMed PMID: 18641677; PMCID: PMC2538690.

32. Markosyan N, Li J, Sun YH, Richman LP, Lin JH, Yan F, Quinones L, Sela Y, Yamazoe T, Gordon N, Tobias JW, Byrne KT, Rech AJ, FitzGerald GA, Stanger BZ, Vonderheide RH. Tumor cell-intrinsic EPHA2 
suppresses anti-tumor immunity by regulating PTGS2 (COX-2). J Clin Invest. 2019;130:3594-609. Epub 2019/06/05. doi: 10.1172/JCI127755. PubMed PMID: 31162144; PMCID: PMC6715369.

33. Reuben A, Chung JW, Lapointe R, Santos MM. The hemochromatosis protein HFE 20 years later: An emerging role in antigen presentation and in the immune system. Immun Inflamm Dis. 2017;5(3):218-32. Epub 2017/05/06. doi: 10.1002/iid3.158. PubMed PMID: 28474781; PMCID: PMC5569368.

845

846

34. Kouo T, Huang L, Pucsek AB, Cao M, Solt S, Armstrong T, Jaffee E. Galectin-3 Shapes Antitumor Immune Responses by Suppressing CD8+ T Cells via LAG-3 and Inhibiting Expansion of Plasmacytoid Dendritic Cells. Cancer Immunol Res. 2015;3(4):412-23. Epub 2015/02/19. doi: 10.1158/23266066.CIR-14-0150. PubMed PMID: 25691328; PMCID: PMC4390508.

35. Canadas I, Thummalapalli R, Kim JW, Kitajima S, Jenkins RW, Christensen CL, Campisi M, Kuang Y, Zhang Y, Gjini E, Zhang G, Tian T, Sen DR, Miao D, Imamura Y, Thai T, Piel B, Terai H, Aref AR, Hagan T, Koyama S, Watanabe M, Baba H, Adeni AE, Lydon CA, Tamayo P, Wei Z, Herlyn M, Barbie TU, Uppaluri R, Sholl LM, Sicinska E, Sands J, Rodig S, Wong KK, Paweletz CP, Watanabe H, Barbie DA. Tumor innate immunity primed by specific interferon-stimulated endogenous retroviruses. Nat Med. 2018;24(8):1143-50. Epub 2018/07/25. doi: 10.1038/s41591-018-0116-5. PubMed PMID: 30038220; PMCID: PMC6082722.

36. Aran D, Lasry A, Zinger A, Biton M, Pikarsky E, Hellman A, Butte AJ, Ben-Neriah Y. Widespread parainflammation in human cancer. Genome Biol. 2016;17(1):145. Epub 2016/07/09. doi:

10.1186/s13059-016-0995-z. PubMed PMID: 27386949; PMCID: PMC4937599.

859

860

37. Coppe JP, Patil CK, Rodier F, Sun Y, Munoz DP, Goldstein J, Nelson PS, Desprez PY, Campisi J. Senescence-associated secretory phenotypes reveal cell-nonautonomous functions of oncogenic RAS and the p53 tumor suppressor. PLoS Biol. 2008;6(12):2853-68. Epub 2008/12/05. doi: 10.1371/journal.pbio.0060301. PubMed PMID: 19053174; PMCID: PMC2592359.

38. Chien Y, Scuoppo C, Wang X, Fang X, Balgley B, Bolden JE, Premsrirut P, Luo W, Chicas A, Lee CS, Kogan SC, Lowe SW. Control of the senescence-associated secretory phenotype by NF-kappaB promotes senescence and enhances chemosensitivity. Genes Dev. 2011;25(20):2125-36. Epub 2011/10/08. doi: 10.1101/gad.17276711. PubMed PMID: 21979375 ; PMCID: PMC3205583.

39. Travaglini KJ, Nabhan AN, Penland L, Sinha R, Gillich A, Sit RV, Chang S, Conley SD, Mori Y, Seita J, Berry GJ, Shrager JB, Metzger RJ, Kuo CS, Neff N, Weissman IL, Quake SR, Krasnow MA. A molecular cell atlas of the human lung from single cell RNA sequencing. bioRxiv. 2019.

40. Zhang H, Deo M, Thompson RC, Uhler MD, Turner DL. Negative regulation of Yap during neuronal differentiation. Dev Biol. 2012;361(1):103-15. Epub 2011/11/01. doi: 10.1016/j.ydbio.2011.10.017. PubMed PMID: 22037235; PMCID: PMC3235039.

41. Schoggins JW. Interferon-Stimulated Genes: What Do They All Do? Annu Rev Virol. 2019;6(1):567-84. Epub 2019/07/10. doi: 10.1146/annurev-virology-092818-015756. PubMed PMID: 31283436.

42. Pfaender S, Mar KB, Michailidis E, Kratzel A, Hirt D, V'kovski P, Fan W, Ebert N, Stalder H, Kleine-Weber H, Hoffmann M, Hoffmann HH, Saeed M, Dijkman R, Steinmann E, Wight-Carter M, Hanners NW, Pöhlmann S, Gallagher T, Todt D, Zimmer G, Rice CM, Schoggins JW, Thiel V. LY6E impairs coronavirus fusion and confers immune control of viral disease. bioRxiv. 2020.

43. Shen LW, Mao HJ, Wu YL, Tanaka Y, Zhang W. TMPRSS2: A potential target for treatment of influenza virus and coronavirus infections. Biochimie. 2017;142:1-10. Epub 2017/08/06. doi: 10.1016/j.biochi.2017.07.016. PubMed PMID: 28778717; PMCID: PMC7116903.

44. Barbie DA, Tamayo P, Boehm JS, Kim SY, Moody SE, Dunn IF, Schinzel AC, Sandy P, Meylan E, Scholl C, Frohling S, Chan EM, Sos ML, Michel K, Mermel C, Silver SJ, Weir BA, Reiling JH, Sheng Q, Gupta PB, Wadlow RC, Le H, Hoersch S, Wittner BS, Ramaswamy S, Livingston DM, Sabatini DM, Meyerson M, Thomas RK, Lander ES, Mesirov JP, Root DE, Gilliland DG, Jacks T, Hahn WC. Systematic RNA interference reveals that oncogenic KRAS-driven cancers require TBK1. Nature. 2009;462(7269):10812. Epub 2009/10/23. doi: 10.1038/nature08460. PubMed PMID: 19847166; PMCID: PMC2783335. 
45. Wang T, Lu R, Kapur P, Jaiswal BS, Hannan R, Zhang Z, Pedrosa I, Luke JJ, Zhang H, Goldstein LD, Yousuf Q, Gu YF, McKenzie T, Joyce A, Kim MS, Wang X, Luo D, Onabolu O, Stevens C, Xie Z, Chen M, Filatenkov A, Torrealba J, Luo X, Guo W, He J, Stawiski E, Modrusan Z, Durinck S, Seshagiri S, Brugarolas J. An Empirical Approach Leveraging Tumorgrafts to Dissect the Tumor Microenvironment in Renal Cell Carcinoma Identifies Missing Link to Prognostic Inflammatory Factors. Cancer Discov. 2018;8(9):1142-55. Epub 2018/06/10. doi: 10.1158/2159-8290.CD-17-1246. PubMed PMID: 29884728; PMCID: PMC6125163.

46. Ayers M, Lunceford J, Nebozhyn M, Murphy E, Loboda A, Kaufman DR, Albright A, Cheng JD, Kang SP, Shankaran V, Piha-Paul SA, Yearley J, Seiwert TY, Ribas A, McClanahan TK. IFN-gammarelated mRNA profile predicts clinical response to PD-1 blockade. J Clin Invest. 2017;127(8):2930-40. Epub 2017/06/27. doi: 10.1172/JCI91190. PubMed PMID: 28650338; PMCID: PMC5531419. 47. Liu Y, He M, Wang D, Diao L, Liu J, Tang L, Guo S, He F, Li D. HisgAtlas 1.0: a human immunosuppression gene database. Database (Oxford). 2017;2017. Epub 2017/01/01. doi: 10.1093/database/bax094. PubMed PMID: 31725860.

48. Lee S, Margolin K. Cytokines in cancer immunotherapy. Cancers (Basel). 2011;3(4):3856-93. Epub 2011/01/01. doi: 10.3390/cancers3043856. PubMed PMID: 24213115; PMCID: PMC3763400. 49. Balanis NG, Sheu KM, Esedebe FN, Patel SJ, Smith BA, Park JW, Alhani S, Gomperts BN, Huang J, Witte ON, Graeber TG. Pan-cancer Convergence to a Small-Cell Neuroendocrine Phenotype that Shares Susceptibilities with Hematological Malignancies. Cancer Cell. 2019;36(1):17-34 e7. Epub 2019/07/10. doi: 10.1016/j.ccell.2019.06.005. PubMed PMID: 31287989; PMCID: PMC6703903. 50. Vivian J, Rao AA, Nothaft FA, Ketchum C, Armstrong J, Novak A, Pfeil J, Narkizian J, Deran AD, Musselman-Brown A, Schmidt H, Amstutz P, Craft B, Goldman M, Rosenbloom K, Cline M, O'Connor B, Hanna M, Birger C, Kent WJ, Patterson DA, Joseph AD, Zhu J, Zaranek S, Getz G, Haussler D, Paten B. Toil enables reproducible, open source, big biomedical data analyses. Nat Biotechnol. 2017;35(4):314-6. Epub 2017/04/12. doi: 10.1038/nbt.3772. PubMed PMID: 28398314; PMCID: PMC5546205. 51. Thorsson V, Gibbs DL, Brown SD, Wolf D, Bortone DS, Ou Yang TH, Porta-Pardo E, Gao GF, Plaisier CL, Eddy JA, Ziv E, Culhane AC, Paull EO, Sivakumar IKA, Gentles AJ, Malhotra R, Farshidfar F, Colaprico A, Parker JS, Mose LE, Vo NS, Liu J, Liu Y, Rader J, Dhankani V, Reynolds SM, Bowlby R, Califano A, Cherniack AD, Anastassiou D, Bedognetti D, Mokrab Y, Newman AM, Rao A, Chen K, Krasnitz A, Hu H, Malta TM, Noushmehr H, Pedamallu CS, Bullman S, Ojesina AI, Lamb A, Zhou W, Shen H, Choueiri TK, Weinstein JN, Guinney J, Saltz J, Holt RA, Rabkin CS, Cancer Genome Atlas Research N, Lazar AJ, Serody JS, Demicco EG, Disis ML, Vincent BG, Shmulevich I. The Immune Landscape of Cancer. Immunity. 2018;48(4):812-30 e14. Epub 2018/04/10. doi: 10.1016/j.immuni.2018.03.023. PubMed PMID: 29628290; PMCID: PMC5982584.

52. Pugh TJ, Morozova O, Attiyeh EF, Asgharzadeh S, Wei JS, Auclair D, Carter SL, Cibulskis K, Hanna M, Kiezun A, Kim J, Lawrence MS, Lichenstein L, McKenna A, Pedamallu CS, Ramos AH, Shefler E, Sivachenko A, Sougnez C, Stewart C, Ally A, Birol I, Chiu R, Corbett RD, Hirst M, Jackman SD, Kamoh B, Khodabakshi AH, Krzywinski M, Lo A, Moore RA, Mungall KL, Qian J, Tam A, Thiessen N, Zhao Y, Cole KA, Diamond M, Diskin SJ, Mosse YP, Wood AC, Ji L, Sposto R, Badgett T, London WB, Moyer Y, GastierFoster JM, Smith MA, Guidry Auvil JM, Gerhard DS, Hogarty MD, Jones SJ, Lander ES, Gabriel SB, Getz G, Seeger RC, Khan J, Marra MA, Meyerson M, Maris JM. The genetic landscape of high-risk neuroblastoma. Nat Genet. 2013;45(3):279-84. Epub 2013/01/22. doi: 10.1038/ng.2529. PubMed PMID: 23334666; PMCID: PMC3682833.

53. Canadas I, Rojo F, Taus A, Arpi O, Arumi-Uria M, Pijuan L, Menendez S, Zazo S, Domine M, Salido M, Mojal S, Garcia de Herreros A, Rovira A, Albanell J, Arriola E. Targeting epithelial-to-mesenchymal transition with Met inhibitors reverts chemoresistance in small cell lung cancer. Clin Cancer Res. 2014;20(4):938-50. Epub 2013/11/29. doi: 10.1158/1078-0432.CCR-13-1330. PubMed PMID: 24284055.

54. Drapkin BJ, George J, Christensen CL, Mino-Kenudson M, Dries R, Sundaresan T, Phat S, Myers DT, Zhong J, Igo P, Hazar-Rethinam MH, Licausi JA, Gomez-Caraballo M, Kem M, Jani KN, Azimi R, 
Abedpour N, Menon R, Lakis S, Heist RS, Buttner R, Haas S, Sequist LV, Shaw AT, Wong KK, Hata AN, Toner M, Maheswaran S, Haber DA, Peifer M, Dyson N, Thomas RK, Farago AF. Genomic and Functional Fidelity of Small Cell Lung Cancer Patient-Derived Xenografts. Cancer Discov. 2018;8(5):600-15. Epub 2018/02/28. doi: 10.1158/2159-8290.CD-17-0935. PubMed PMID: 29483136; PMCID: PMC6369413.

942

943

944

945

946

947

948

949

950

951

952

953

954

955

956

957

958

959

960

961

962

963

964

965

966

967

968

969

970

971

972

973

974

975

976

977

978

979

980

981

982

983

984

985

986

987

988

55. Ireland AS, Micinski AM, Kastner DW, Guo B, Wait SJ, Spainhower KB, Conley CC, Chen OS, Guthrie MR, Soltero D, Qiao Y, Huang X, Tarapcsak S, Devarakonda S, Chalishazar MD, Gertz J, Moser JC, Marth G, Puri S, Witt BL, Spike BT, Oliver TG. MYC Drives Temporal Evolution of Small Cell Lung Cancer Subtypes by Reprogramming Neuroendocrine Fate. Cancer Cell. 2020. Epub 2020/06/01. doi: 10.1016/j.ccell.2020.05.001. PubMed PMID: 32473656.

56. Huang YH, Klingbeil O, He XY, Wu XS, Arun G, Lu B, Somerville TDD, Milazzo JP, Wilkinson JE, Demerdash OE, Spector DL, Egeblad M, Shi J, Vakoc CR. POU2F3 is a master regulator of a tuft cell-like variant of small cell lung cancer. Genes Dev. 2018;32(13-14):915-28. Epub 2018/06/28. doi:

10.1101/gad.314815.118. PubMed PMID: 29945888; PMCID: PMC6075037.

57. Park KS, Liang MC, Raiser DM, Zamponi R, Roach RR, Curtis SJ, Walton Z, Schaffer BE, Roake CM, Zmoos AF, Kriegel C, Wong KK, Sage J, Kim CF. Characterization of the cell of origin for small cell lung cancer. Cell Cycle. 2011;10(16):2806-15. Epub 2011/08/09. doi: 10.4161/cc.10.16.17012. PubMed PMID: 21822053; PMCID: PMC3219544.

58. Semenova EA, Nagel R, Berns A. Origins, genetic landscape, and emerging therapies of small cell lung cancer. Genes Dev. 2015;29(14):1447-62. Epub 2015/07/30. doi: 10.1101/gad.263145.115. PubMed PMID: 26220992; PMCID: PMC4526731.

59. Yang D, Denny SK, Greenside PG, Chaikovsky AC, Brady JJ, Ouadah Y, Granja JM, Jahchan NS, Lim JS, Kwok S, Kong CS, Berghoff AS, Schmitt A, Reinhardt HC, Park KS, Preusser M, Kundaje A, Greenleaf WJ, Sage J, Winslow MM. Intertumoral Heterogeneity in SCLC Is Influenced by the Cell Type of Origin. Cancer Discov. 2018;8(10):1316-31. Epub 2018/09/20. doi: 10.1158/2159-8290.CD-17-0987. PubMed PMID: 30228179; PMCID: PMC6195211.

60. Gazdar AF, Savage TK, Johnson JE, Berns A, Sage J, Linnoila RI, MacPherson D, McFadden DG, Farago A, Jacks T, Travis WD, Brambilla E. The comparative pathology of genetically engineered mouse models for neuroendocrine carcinomas of the lung. J Thorac Oncol. 2015;10(4):553-64. Epub 2015/02/13. doi: 10.1097/JT0.0000000000000459. PubMed PMID: 25675280; PMCID: PMC4523224. 61. Vivier E, Raulet DH, Moretta A, Caligiuri MA, Zitvogel L, Lanier LL, Yokoyama WM, Ugolini S. Innate or adaptive immunity? The example of natural killer cells. Science. 2011;331(6013):44-9. Epub 2011/01/08. doi: 10.1126/science.1198687. PubMed PMID: 21212348; PMCID: PMC3089969.

62. Jiang L, Huang J, Higgs BW, Hu Z, Xiao Z, Yao X, Conley S, Zhong H, Liu Z, Brohawn P, Shen D, Wu S, Ge X, Jiang Y, Zhao Y, Lou Y, Morehouse C, Zhu W, Sebastian Y, Czapiga M, Oganesyan V, Fu H, Niu Y, Zhang W, Streicher K, Tice D, Zhao H, Zhu M, Xu L, Herbst R, Su X, Gu Y, Li S, Huang L, Gu J, Han B, Jallal B, Shen H, Yao Y. Genomic Landscape Survey Identifies SRSF1 as a Key Oncodriver in Small Cell Lung Cancer. PLoS Genet. 2016;12(4):e1005895. Epub 2016/04/20. doi: 10.1371/journal.pgen.1005895. PubMed PMID: 27093186; PMCID: PMC4836692.

63. Cai L, Lin S, Girard L, Zhou Y, Yang L, Ci B, Zhou Q, Luo D, Yao B, Tang H, Allen J, Huffman K, Gazdar A, Heymach J, Wistuba I, Xiao G, Minna J, Xie Y. LCE: an open web portal to explore gene expression and clinical associations in lung cancer. Oncogene. 2019;38(14):2551-64. Epub 2018/12/12. doi: 10.1038/s41388-018-0588-2. PubMed PMID: 30532070; PMCID: PMC6477796. 64. Rousseaux S, Debernardi A, Jacquiau B, Vitte AL, Vesin A, Nagy-Mignotte H, Moro-Sibilot D, Brichon PY, Lantuejoul S, Hainaut P, Laffaire J, de Reynies A, Beer DG, Timsit JF, Brambilla C, Brambilla E, Khochbin S. Ectopic activation of germline and placental genes identifies aggressive metastasisprone lung cancers. Sci Transl Med. 2013;5(186):186ra66. Epub 2013/05/24. doi: 10.1126/scitranslmed.3005723. PubMed PMID: 23698379; PMCID: PMC4818008.

65. Ruscetti M, Leibold J, Bott MJ, Fennell M, Kulick A, Salgado NR, Chen CC, Ho YJ, Sanchez-Rivera FJ, Feucht J, Baslan T, Tian S, Chen HA, Romesser PB, Poirier JT, Rudin CM, de Stanchina E, Manchado E, Sherr CJ, Lowe SW. NK cell-mediated cytotoxicity contributes to tumor control by a cytostatic drug 
combination. Science. 2018;362(6421):1416-22. Epub 2018/12/24. doi: 10.1126/science.aas9090. PubMed PMID: 30573629; PMCID: PMC6711172.

991 66. Dang J, Tiwari SK, Lichinchi G, Qin Y, Patil VS, Eroshkin AM, Rana TM. Zika Virus Depletes Neural Progenitors in Human Cerebral Organoids through Activation of the Innate Immune Receptor TLR3. Cell Stem Cell. 2016;19(2):258-65. Epub 2016/05/11. doi: 10.1016/j.stem.2016.04.014.

995

996

997 PubMed PMID: 27162029; PMCID: PMC5116380.

67. Eden E, Navon R, Steinfeld I, Lipson D, Yakhini Z. GOrilla: a tool for discovery and visualization of enriched GO terms in ranked gene lists. BMC Bioinformatics. 2009;10:48. Epub 2009/02/05. doi: 10.1186/1471-2105-10-48. PubMed PMID: 19192299; PMCID: PMC2644678.

998

999

000

001

002

003

004

005

006

007

008

009

010

011

012

013

014

015

016

017

018

019

020

021

022

023

024

025

026

027

028

029

030

031

032

033

034

035

036

037 Acids Res. 2019;47(D1):D330-D8. Epub 2018/11/06. doi: 10.1093/nar/gky1055. PubMed PMID: $30395331 ;$ PMCID: PMC6323945.

69. Supek F, Bosnjak M, Skunca N, Smuc T. REVIGO summarizes and visualizes long lists of gene ontology terms. PLoS One. 2011;6(7):e21800. Epub 2011/07/27. doi: 10.1371/journal.pone.0021800. PubMed PMID: 21789182; PMCID: PMC3138752.

70. Sergushichev A. An algorithm for fast preranked gene set enrichment analysis using cumulative statistic calculation. bioRxiv. 2016.

71. Gu Z, Eils R, Schlesner M. Complex heatmaps reveal patterns and correlations in multidimensional genomic data. Bioinformatics. 2016;32(18):2847-9. Epub 2016/05/22. doi: 10.1093/bioinformatics/btw313. PubMed PMID: 27207943.

72. Wickham H. ggplot2: Elegant Graphics for Data Analysis. Springer-Verlag New York; 2016.

73. Wilke CO. ggridges: Ridgeline Plots in 'ggplot2. 2020.

74. Slowikowski K. ggrepel: Automatically Position Non-Overlapping Text Labels with 'ggplot2'. 2019.

75. Kassambara A. ggpubr: 'ggplot2' Based Publication Ready Plots. 2020.

76. Tennekes M. treemap: Treemap Visualization. 2017.

77. Neuwirth E. RColorBrewer: ColorBrewer Palettes. 2014.

78. Huling J. jcolors: Colors Palettes for R and 'ggplot2', Additional Themes for 'ggplot2'. 2020.

79. Pedersen TL. patchwork: The Composer of Plots. 2019.

80. Davis S, Meltzer PS. GEOquery: a bridge between the Gene Expression Omnibus (GEO) and BioConductor. Bioinformatics. 2007;23(14):1846-7. Epub 2007/05/15. doi:

10.1093/bioinformatics/btm254. PubMed PMID: 17496320.

81. Bolstad B. preprocessCore: A collection of pre-processing functions. 2019.

82. Moon KR, van Dijk D, Wang Z, Gigante S, Burkhardt DB, Chen WS, Yim K, Elzen AVD, Hirn MJ, Coifman RR, Ivanova NB, Wolf G, Krishnaswamy S. Visualizing structure and transitions in highdimensional biological data. Nat Biotechnol. 2019;37(12):1482-92. Epub 2019/12/05. doi: 10.1038/s41587-019-0336-3. PubMed PMID: 31796933; PMCID: PMC7073148.

83. Cilloniz C, Pantin-Jackwood MJ, Ni C, Carter VS, Korth MJ, Swayne DE, Tumpey TM, Katze MG. Molecular signatures associated with Mx1-mediated resistance to highly pathogenic influenza virus infection: mechanisms of survival. J Virol. 2012;86(5):2437-46. Epub 2011/12/23. doi: 10.1128/JVI.06156-11. PubMed PMID: 22190720; PMCID: PMC3302269.

84. Rusinova I, Forster S, Yu S, Kannan A, Masse M, Cumming H, Chapman R, Hertzog PJ. Interferome v2.0: an updated database of annotated interferon-regulated genes. Nucleic Acids Res. 2013;41(Database issue):D1040-6. Epub 2012/12/04. doi: 10.1093/nar/gks1215. PubMed PMID: 23203888; PMCID: PMC3531205.

85. Liberzon A, Birger C, Thorvaldsdottir H, Ghandi M, Mesirov JP, Tamayo P. The Molecular Signatures Database (MSigDB) hallmark gene set collection. Cell Syst. 2015;1(6):417-25. Epub 2016/01/16. doi: 10.1016/j.cels.2015.12.004. PubMed PMID: 26771021; PMCID: PMC4707969. 
86. Eppig JT. Mouse Genome Informatics (MGI) Resource: Genetic, Genomic, and Biological Knowledgebase for the Laboratory Mouse. ILAR J. 2017;58(1):17-41. Epub 2017/08/26. doi: 10.1093/ilar/ilx013. PubMed PMID: 28838066; PMCID: PMC5886341. seq data. BMC Bioinformatics. 2013;14:7. Epub 2013/01/18. doi: 10.1186/1471-2105-14-7. PubMed PMID: 23323831; PMCID: PMC3618321.

88. Parra ER, Behrens C, Rodriguez-Canales J, Lin H, Mino B, Blando J, Zhang J, Gibbons DL, Heymach JV, Sepesi B, Swisher SG, Weissferdt A, Kalhor N, Izzo J, Kadara H, Moran C, Lee JJ, Wistuba, II. Image Analysis-based Assessment of PD-L1 and Tumor-Associated Immune Cells Density Supports Distinct Intratumoral Microenvironment Groups in Non-small Cell Lung Carcinoma Patients. Clin Cancer Res. 2016;22(24):6278-89. Epub 2016/06/03. doi: 10.1158/1078-0432.CCR-15-2443. PubMed PMID: 27252415; PMCID: PMC5558040.

89. Fujimoto J, Kadara H, Garcia MM, Kabbout M, Behrens C, Liu DD, Lee JJ, Solis LM, Kim ES, Kalhor N, Moran C, Sharafkhaneh A, Lotan R, Wistuba, II. G-protein coupled receptor family C, group 5, member A (GPRC5A) expression is decreased in the adjacent field and normal bronchial epithelia of patients with chronic obstructive pulmonary disease and non-small-cell lung cancer. J Thorac Oncol. 2012;7(12):1747-54. Epub 2012/11/17. doi: 10.1097/JT0.0b013e31826bb1ff. PubMed PMID: 23154545; PMCID: PMC3622592.

90. Tang C, Hobbs B, Amer A, Li X, Behrens C, Canales JR, Cuentas EP, Villalobos P, Fried D, Chang JY, Hong DS, Welsh JW, Sepesi B, Court L, Wistuba, II, Koay EJ. Development of an Immune-Pathology Informed Radiomics Model for Non-Small Cell Lung Cancer. Sci Rep. 2018;8(1):1922. Epub 2018/02/02. doi: 10.1038/s41598-018-20471-5. PubMed PMID: $29386574 ;$ PMCID: PMC5792427. 91. Gautier L, Cope L, Bolstad BM, Irizarry RA. affy--analysis of Affymetrix GeneChip data at the probe level. Bioinformatics. 2004;20(3):307-15. Epub 2004/02/13. doi:

10.1093/bioinformatics/btg405. PubMed PMID: 14960456.

92. Dai M, Wang P, Boyd AD, Kostov G, Athey B, Jones EG, Bunney WE, Myers RM, Speed TP, Akil H, Watson SJ, Meng F. Evolving gene/transcript definitions significantly alter the interpretation of GeneChip data. Nucleic Acids Res. 2005;33(20):e175. Epub 2005/11/15. doi: 10.1093/nar/gni179. PubMed PMID: 16284200; PMCID: PMC1283542.

93. Dobin A, Davis CA, Schlesinger F, Drenkow J, Zaleski C, Jha S, Batut P, Chaisson M, Gingeras TR. STAR: ultrafast universal RNA-seq aligner. Bioinformatics. 2013;29(1):15-21. Epub 2012/10/30. doi: 10.1093/bioinformatics/bts635. PubMed PMID: 23104886; PMCID: PMC3530905.

94. Trapnell C, Williams BA, Pertea G, Mortazavi A, Kwan G, van Baren MJ, Salzberg SL, Wold BJ, Pachter L. Transcript assembly and quantification by RNA-Seq reveals unannotated transcripts and isoform switching during cell differentiation. Nat Biotechnol. 2010;28(5):511-5. Epub 2010/05/04. doi: 10.1038/nbt.1621. PubMed PMID: 20436464; PMCID: PMC3146043.

95. Bullard JH, Purdom E, Hansen KD, Dudoit S. Evaluation of statistical methods for normalization and differential expression in mRNA-Seq experiments. BMC Bioinformatics. 2010;11:94. Epub 2010/02/20. doi: 10.1186/1471-2105-11-94. PubMed PMID: 20167110 ; PMCID: PMC2838869. 96. Ritz C, Baty F, Streibig JC, Gerhard D. Dose-Response Analysis Using R. PLoS One. 2015;10(12):e0146021. Epub 2015/12/31. doi: 10.1371/journal.pone.0146021. PubMed PMID: 26717316; PMCID: PMC4696819.

97. McMillan EA, Ryu MJ, Diep CH, Mendiratta S, Clemenceau JR, Vaden RM, Kim JH, Motoyaji T, Covington KR, Peyton M, Huffman K, Wu X, Girard L, Sung Y, Chen PH, Mallipeddi PL, Lee JY, Hanson J, Voruganti S, Yu Y, Park S, Sudderth J, DeSevo C, Muzny DM, Doddapaneni H, Gazdar A, Gibbs RA, Hwang TH, Heymach JV, Wistuba I, Coombes KR, Williams NS, Wheeler DA, MacMillan JB, Deberardinis RJ, Roth MG, Posner BA, Minna JD, Kim HS, White MA. Chemistry-First Approach for Nomination of Personalized Treatment in Lung Cancer. Cell. 2018;173(4):864-78 e29. Epub 2018/04/24. doi: 10.1016/j.cell.2018.03.028. PubMed PMID: 29681454; PMCID: PMC5935540. 
Figures

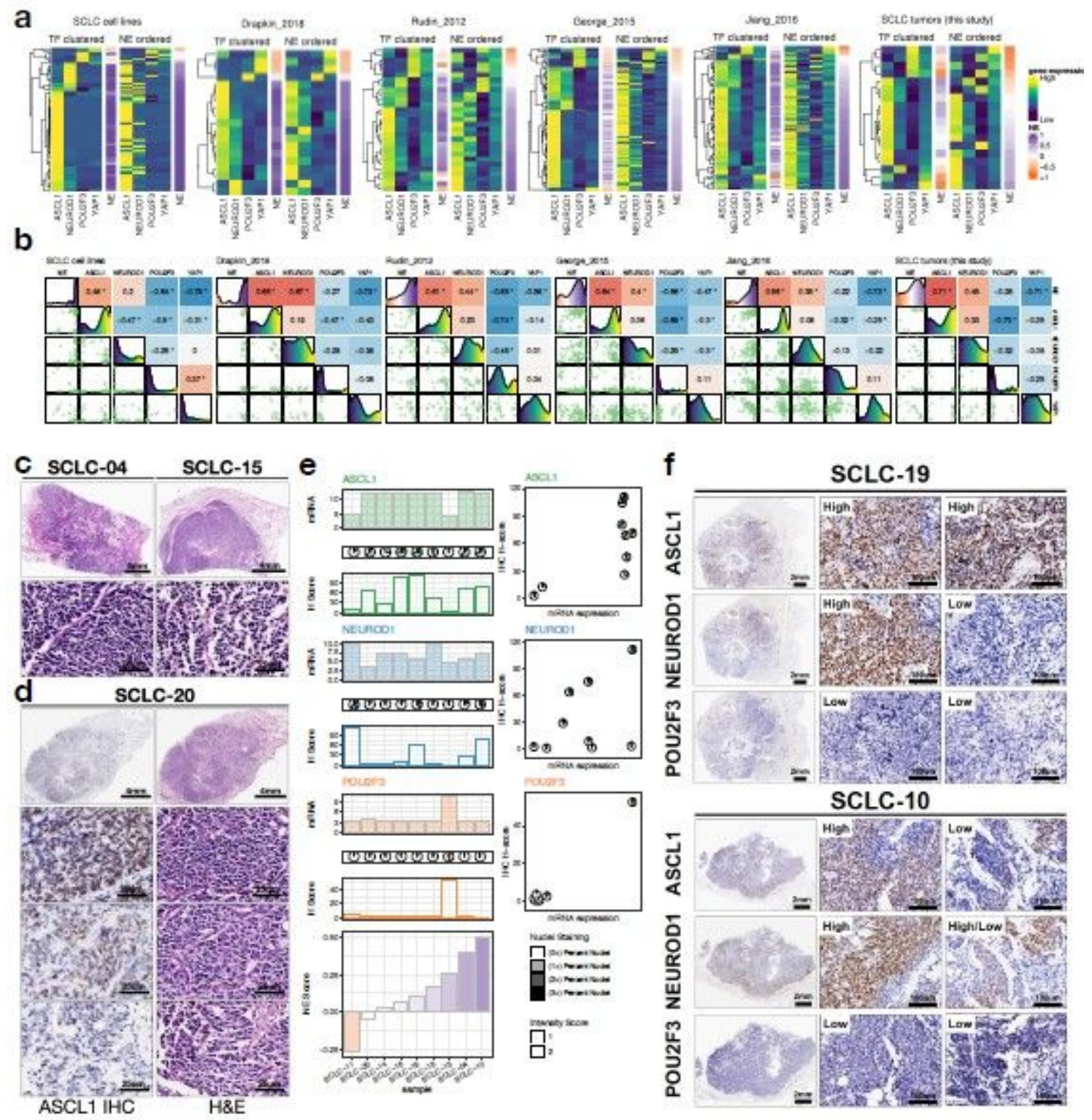

Figure 1

NE score and SCLC molecular subtypes a, Heatmaps visualizing expression of molecular subtype-specific TFs and NE scores. Two heatmaps were generated for each study, with one ordered by complete linkage hierarchical clustering of TFs and the other ordered by NE scores. b, Pairwise associations among NE scores and molecular subtype-specific TFs. Lower left panels are scatter plots, diagonal line panels are density plots and upper right panel shows correlation coefficients from pairwise Pearson correlation. *, pvalue < 0.05. c, H\&E staining of two high NE score SCLC tumor samples showing classic SCLC morphology with dark nuclei, scant cytoplasm and inconspicuous nucleoli. d, ASCL1 IHC staining and H\&E staining of a low NE-score SCLC tumor, showing variable morphology at different selected areas, where ASCL1-low areas appear to be more variant-like e, Quantifications of TF expression from IHC staining or microarray profiling, samples are ordered by increasing NE scores. $f$, IHC of ASCL1, NEUROD1 
and POU2F3 in two tumors that express both ASCL1 and NEUROD1. Two areas per tumor were selected for showing intratumoral heterogeneity in ASCL1 and NEUROD1 expression patterns.

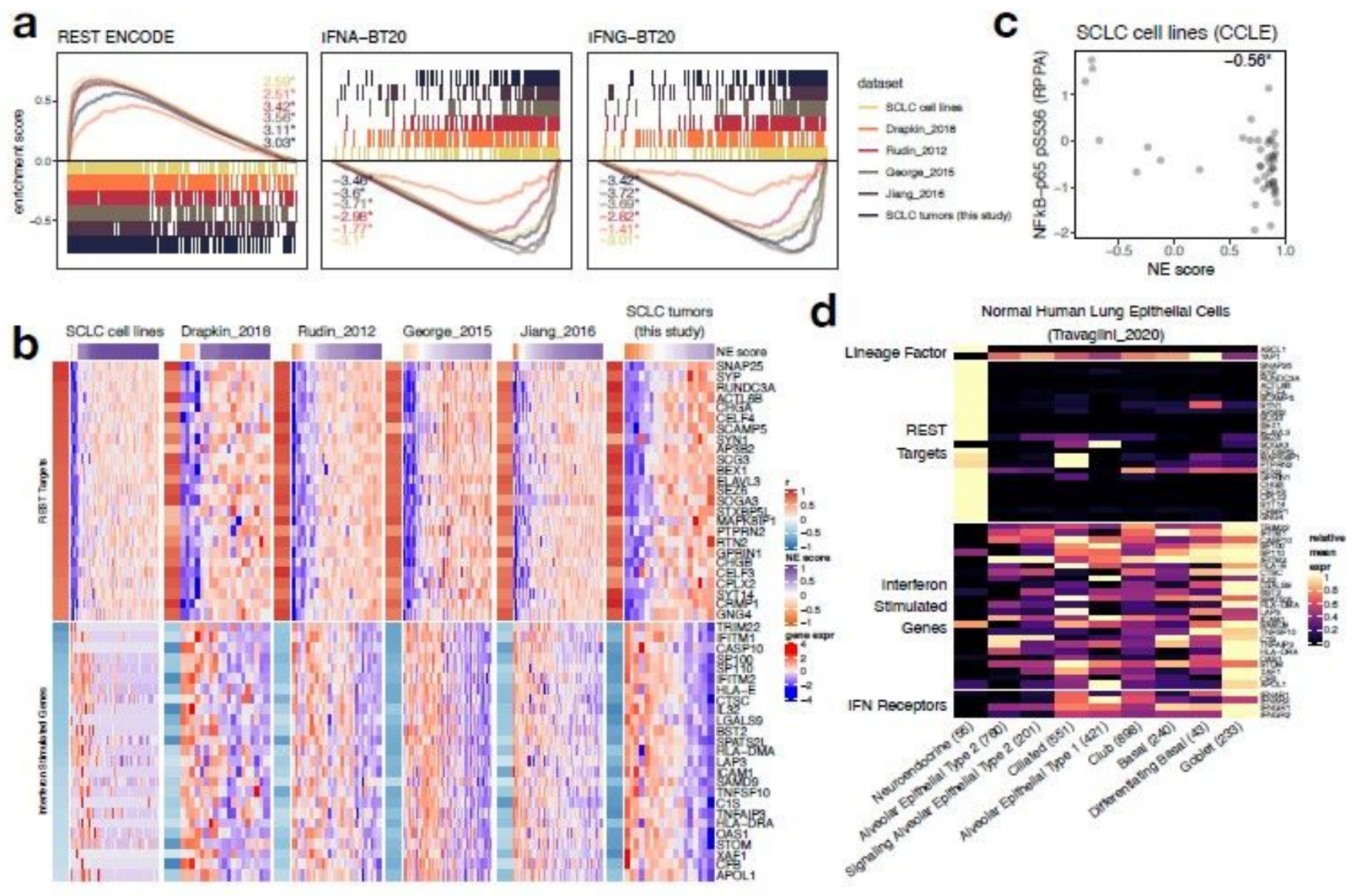

\section{Figure 2}

Repression of ISGs in high NE-score SCLC and PNECs a, GSEA enrichment plots for selected genesets. Results from SCLC cell lines, PDXs (Drapkin_2018) and patient tumor datasets were superimposed. Normalized enrichment score (NES) were provided. *, multiple comparison adjusted p-value $<0.05$. b, Heatmaps for top 25 leading edge genes selected from genesets in (a). Gene expression matrix of each dataset was annotated with color-coded Pearson correlation coefficient (from correlating NE score with gene expression) as a left-side column, and a top bar indicating NE scores. c, Scatter plots showing negative correlation between NE score and Ser536 phosphorylation on NFkB-p65 in SCLC cell lines. Pearson correlation coefficient was provided. *, $p$-value $<0.05$. $d$, Heatmap showing relative expression of selected lineage factors (ASCL1 and YAP1), REST targets and ISGs (same genes as used in b, determined from a) as well as interferon receptor genes in healthy human lung epithelial cells based on scRNA-seq experiments. 


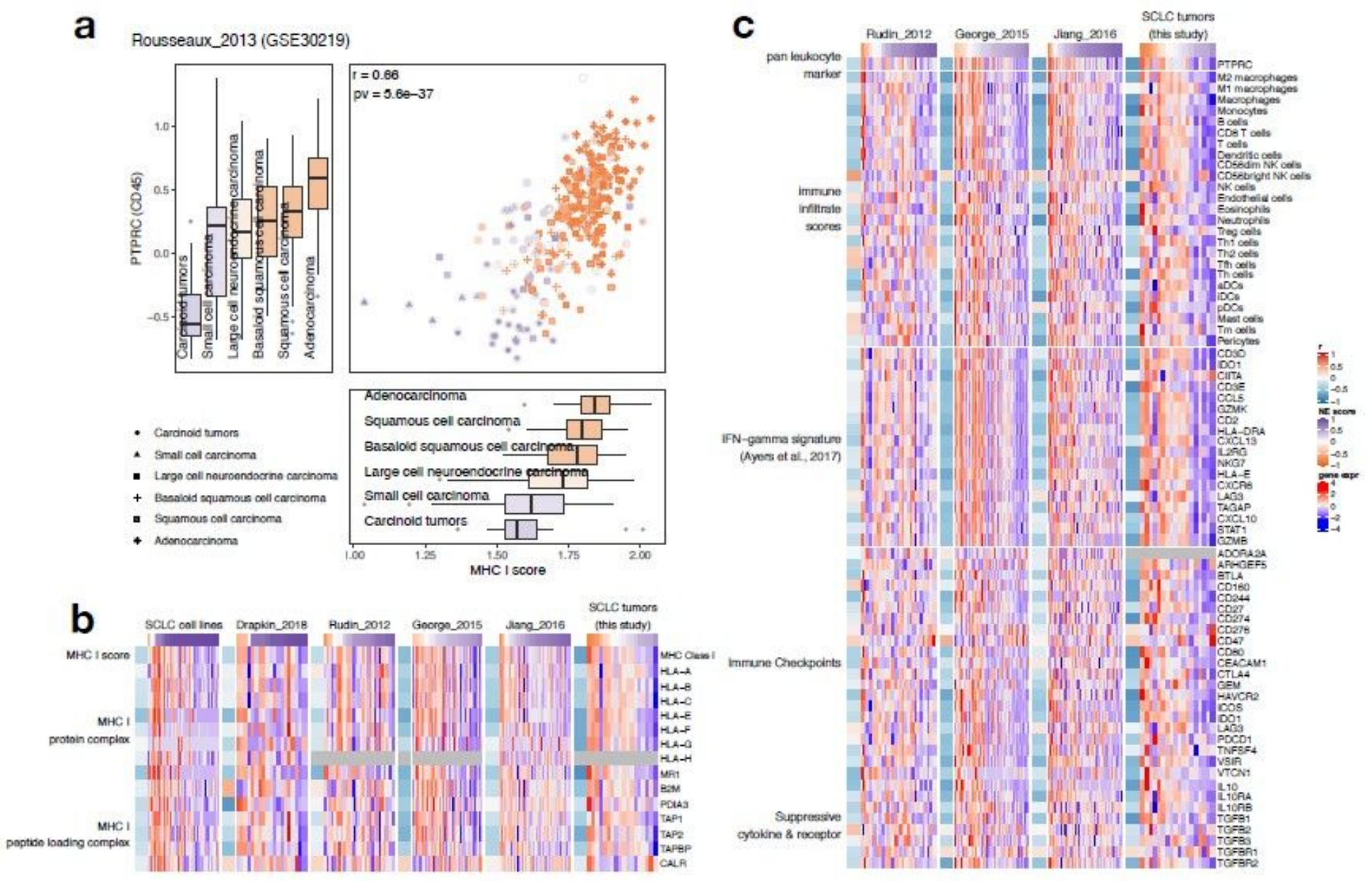

Figure 3

Low NE-score variant SCLC have increased tumor-immune interaction a, Expression of MHC I genes and pan-leukocyte marker PTPRC 361 in lung tumors from the "Rousseaux_2013" dataset. Box whisker plots are filled with color reflecting the median NE score in different histological subtypes. Color for scatterplot symbols reflects NE score for different samples. b, Heatmaps visualizing expression of MHC I genes across multiple SCLC datasets. c, Heatmaps visualizing expression of PTPRC, immune-cell-type-specific signature scores, PD-1 blockade response-predicting IFN gamma related signature genes (46), immune checkpoint genes and suppressive cytokines and receptors in SCLC tumor datasets. 

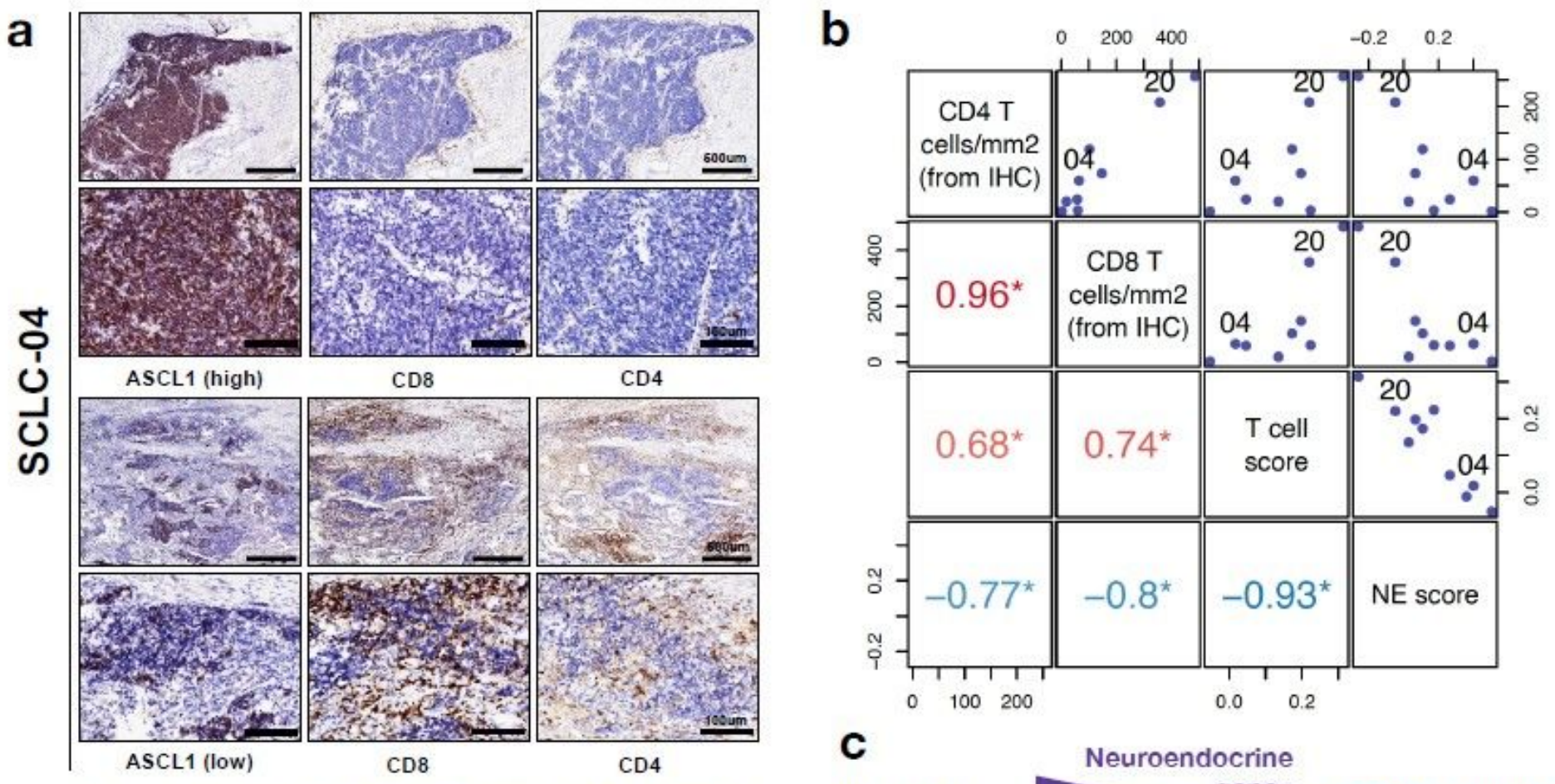

C

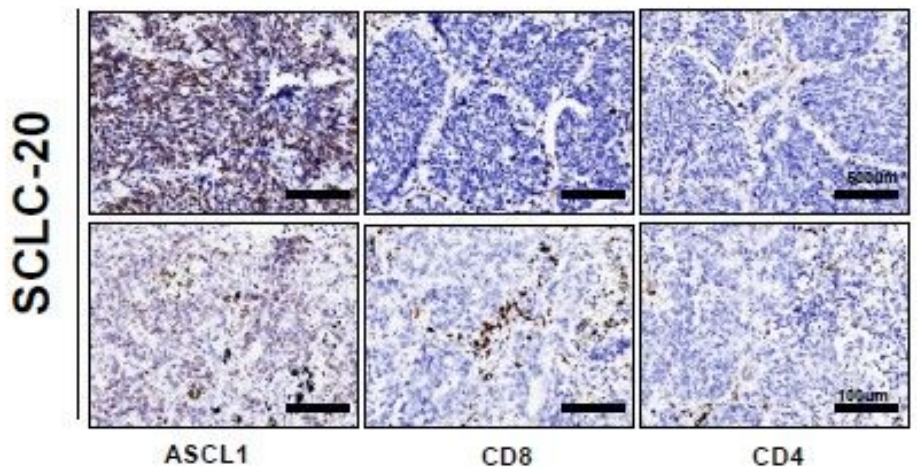

\section{NE lineage \\ Normal cells \\ PNECS \\ (stem cells)}

Classic NETs

Classic SCLC

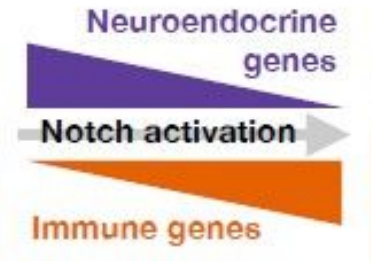

Tumor-immune Interaction
non-NE lineage

Normal cells

Other lung epithelial cells

Variant NETs

Variant SCLC

\section{Figure 4}

Intertumoral and intratumoral heterogeneity in T cell infiltration from SCLC tumors with variable NE features a, IHC of ASCL1, CD4 and CD8 in selected tumors. SCLC-04 is a SCLC tumor with NE score of 0.4. CD8 or CD4 T cells were few in the ASCL1-high regions but abundant in the ASCL1-low region; SCLC20 is a tumor with NE score of -0.05 , similar reciprocal relationship of ASCL1 staining and T cell infiltration was observed. Representative regions with high or low ASCL1 staining were shown. b, Relationship between IHC-determined per area CD4 and CD8 T cell count, gene expression-based T cell score and NE score in all 9 tumors assessed. Scatter plots and Pearson correlation coefficients were provided for assessment of pairwise correlations. *, Pearson correlation with p-value $<0.05$. c, Schematic diagram showing relationship between neuroendocrine and immune gene expression in normal cells and neuroendocrine tumors (NETs). 


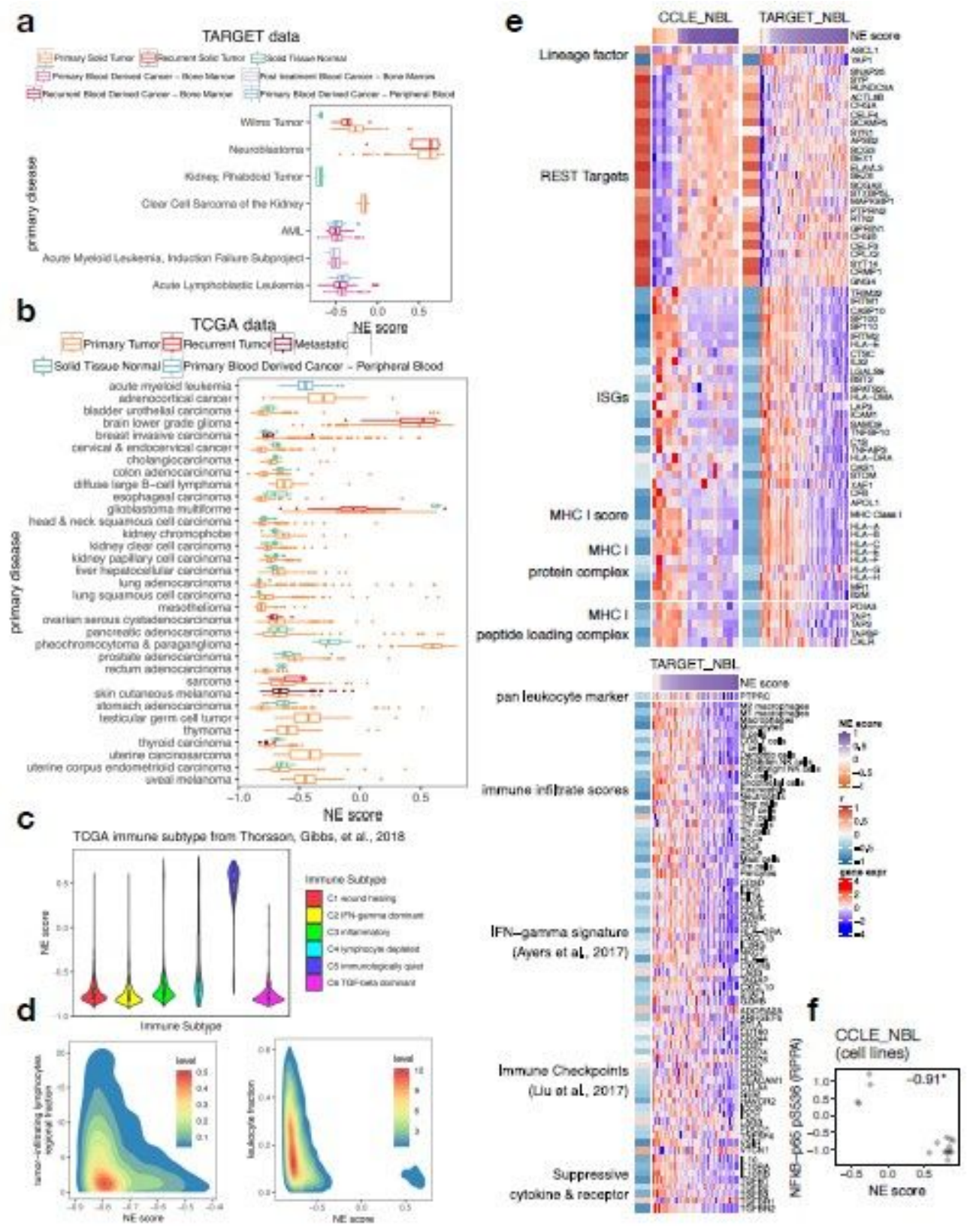

\section{Figure 5}

Relationship between NE scores and immune phenotypes in pan-cancer samples a-b, NE scores of pancancer samples in the TARGET pediatric cancer cohorts (a) and TCGA adult cancer cohorts (b). c, NE scores by immune subtype in TCGA pan-cancer samples. $d$, Relationship between NE scores and tumorinfiltrating lymphocytes regional fraction or leukocyte fraction in TCGA pan-cancer samples. e, Heatmap visualizing expression of various genes and summary scores previously assessed for SCLC and now in NBL with cell line and tumor datasets side-by-side. f, Scatter plots showing negativecorrelation between NE score and Ser536 phosphorylation on NFkB-p65 in NBL cell lines. Pearson correlation coefficient was provided. *, p-value $<0.05$. 


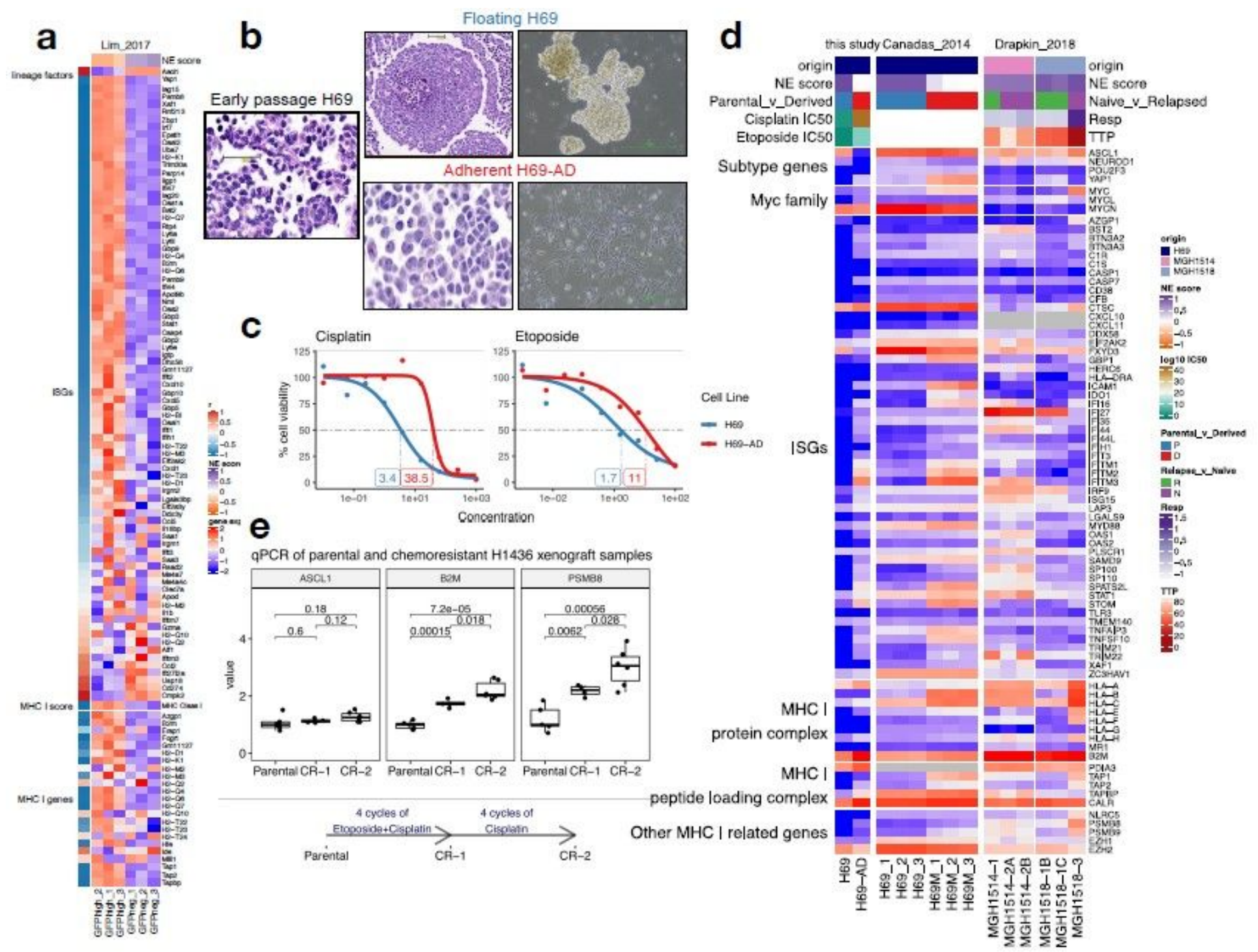

Figure 6

$\mathrm{MHC}$ I upregulation in chemoresistant 389 SCLC a, Heatmap visualizing increased expression of ISGs, MHC I genes as cells switch from Ascl1 + to Yap1+ in SCLC GEMM tumors from the "Lim_2017" . GFP was expressed from endogenous promoter of a Notch target gene Hes1 in Rb-/-/p53-/-/p130-/- (TKO) background. Using flow cytometry, the authors first sorted out SCLC tumor cells and then further sorted by GFP to obtain relatively pure tumor cells with different Notch activation status. Three biological replicates were each provided for GFP negative (Notch inactive, classic high-NE) cells and GFP positive cells (Notch active, low-NE). b, Different morphology and culture characteristics of adherent H69-AD and the parental H69. c, Dose response curves for Cisplatin and Etoposide in the H69 cell line pair. Note that H69-AD, the adherent line, is more resistant with higher IC50s. d, Expression changes of selected genes in: H69 cell line pair from this study, H69 and derived mesenchymal H69M cell lines from "Canadas_2014" and autologous PDX samples before and after chemotherapy from “Drapkin_2018”. PDX parameters: TTP, time to progression, defined by time to $2 x$ initial tumor volume; RESP, change in tumor volume between initial tumor volume and minimum of day 14-28. Relapsed sample from MGH-1514 did not show increased chemoresistance based on the RESP and TTP parameters. Note that unlike other heatmaps, 
due to the small number of samples in each dataset, expression is not scaled by gene in this heatmap. e, qPCR measurement of normalized ASCL1, B2M and PSMB8 expression in naïve parental and chemoresistant $\mathrm{H} 1436$ xenograft tumors.

\section{Supplementary Files}

This is a list of supplementary files associated with this preprint. Click to download.

- supplementaryfigures.pdf

- nrreportingsummary.pdf

- supplementarytables.xIsx 